\title{
1 Regulation of stem cell identity by miR-200a during spinal cord regeneration
}

3 Sarah E. Walker ${ }^{3, \alpha}$, Keith Z. Sabin ${ }^{1,3, \alpha}$, Micah D. Gearhart ${ }^{2}$, Kenta Yamamoto ${ }^{2}$ and Karen

4 Echeverri ${ }^{3, *}$

6 1. Current Address: Stowers Institute for Medical Research, Kansas City, MO, USA

7 2. University of Minnesota, Minneapolis, MN, USA

8 3. Eugene Bell Center for Regenerative Biology and Tissue Engineering, Marine

9 Biological Laboratory, Woods Hole, MA, USA

11 These authors contributed equally to the work.

$12{ }^{*}$ Corresponding author: kecheverri@mbl.edu

14 Key words: axolotl, spinal cord, stem cell, mesoderm, regeneration

16 Summary Statement: After spinal cord injury, miR-200 fine-tunes expression levels

17 brachyury and $\beta$-catenin to direct spinal cord stem into cells of the mesodermal or

18 ectodermal lineage.

\section{Abstract}

21 Axolotls are an important model organism for multiple types of regeneration, including

22 functional spinal cord regeneration. Remarkably, axolotls can repair their spinal cord

23 after a small lesion injury and can also regenerate their entire tail following amputation.

24 Several classical signaling pathways that are used during development are reactivated

25 during regeneration, but how this is regulated remains a mystery. We have previously

26 identified miR-200a as a key factor that promotes successful spinal cord regeneration.

27 Here, using RNA-seq analysis, we discovered that the inhibition of miR-200a results in

28 an upregulation of the classical mesodermal marker brachyury in spinal cord cells after

29 injury. However, these cells still express the neural stem cell marker sox2. In vivo

30 lineage tracing allowed us to determine that these cells can give rise to cells of both the

31 neural and mesoderm lineage. Additionally, we found that miR-200a can directly

32 regulate brachyury via a seed sequence in the 3'UTR of the gene. Our data indicate that

33 miR-200a represses mesodermal cell fate after a small lesion injury in the spinal cord

34 when only glial cells and neurons need to be replaced. 


\section{Introduction}

Regeneration has been observed throughout the plant and animal kingdoms for many years (Sanchez Alvarado and Tsonis, 2006). Among vertebrates, the Mexican axolotl salamander has the remarkable ability to faithfully regenerate its spinal cord after injury. This process has been most commonly studied in the context of tail amputation (McHedlishvili et al., 2012, Monaghan et al., 2007, Piatt, 1955, Rodrigo Albors et al.,

42 2015, Zhang et al., 2000, Zhang et al., 2002a), but the axolotl spinal cord also

43 regenerates after a more targeted transection injury (Butler and Ward, 1965, Butler and

44 Ward, 1967, Clarke et al., 1988, O'Hara et al., 1992, Zukor et al., 2011). These lines of

45 investigation have identified a population of $\mathrm{Sox}^{+} / \mathrm{GFAP}^{+}$glial cells that function as bona

46 fide neural stem cells (NSCs) in the axolotl spinal cord (Echeverri and Tanaka, 2002, Fei

47 et al., 2016, Fei et al., 2014a, McHedlishvili et al., 2012, Rodrigo Albors et al., 2015) .

48 These Sox ${ }^{+} / \mathrm{GFAP}^{+}$NSCs proliferate after injury and differentiate into new glia and

49 neurons (Echeverri and Tanaka, 2002, McHedlishvili et al., 2012, Rodrigo Albors et al.,

50 2015). Inhibition of NSC function by CRISPR/Cas9-mediated knockout of Sox2 results in

51 deficient regenerative outgrowth of the spinal cord after tail amputation (Fei et al., 2016,

52 Fei et al., 2014a).

53 Molecular signals required for the NSC response to injury have been identified

54 after both tail amputation and spinal cord transection. Sonic hedgehog, Wnt/PCP, and

55 Fgf signaling are indispensable for the pro-regenerative NSC response to tail amputation

56 (Rodrigo Albors et al., 2015, Schnapp et al., 2005, Zhang et al., 2000, Zhang et al.,

57 2002a). During spinal cord regeneration after transection, the transcriptional complex

$58 \mathrm{AP}-1^{\mathrm{CFos} / J u n B}$ and MAP kinase signaling are critical regulators of the NSC response to

59 injury (Sabin et al., 2015a, Sabin et al., 2019). Additionally, microRNA (miRNA) signaling

60 is important to fine-tune the NSC response to injury after both tail amputation and spinal

61 cord transection (Diaz Quiroz et al., 2014, Gearhart et al., 2015, Lepp and Carlone,

62 2014, Sehm et al., 2009).

63 We previously demonstrated that miR-200a is an important regulator of the glial

64 cell response after spinal cord transection (Sabin et al., 2019). The function of miR-200a

65 has been most extensively studied during neurodevelopment and epithelial-to-

66 mesenchymal transition (EMT) (Trumbach and Prakash, 2015, Zaravinos, 2015). miR-

67200 a functions to inhibit EMT by directly repressing the expression of the transcription

68 factor $\beta$-catenin (Su et al., 2012, Zaravinos, 2015). This leads to maintained epithelial 
polarity and decreased Wnt signaling. During neurodevelopment, miR-200 family members regulate many processes: neuronal survival (Karres et al., 2007), neuroepithelial progenitor proliferation, NSC identity and neuroblast transition (Morante et al., 2013), neural progenitor identity and cell cycle dynamics (Peng et al., 2012), as well as fine tunes signaling networks necessary for neurogenesis (Choi et al., 2008, Vallejo et al., 2011) and gliogenesis (Buller et al., 2012).

Early experiments aimed at determining the potential of $\mathrm{GFAP}^{+} / \mathrm{Sox}^{+} \mathrm{NSCs}$ prospectively labeled these cells with the Glial fibrillary acidic protein (GFAP) promoter driving GFP expression and used live in vivo fluorescence imaging to follow $\mathrm{GFP}^{+}$glial cells after tail amputation. Most GFP ${ }^{+}$NSCs gave rise to new neurons and glia but a small proportion of labeled cells left the spinal cord and contributed to muscle and cartilage within the regenerated tail (Echeverri and Tanaka, 2002). Similar experiments using grafting of $\mathrm{GFP}^{+}$spinal cords into non-transgenic animals further confirmed that

82 spinal cord cells exited the spinal cord and contributed to cells of other lineages during 83 tail regeneration (McHedlishvili et al., 2007).

84 Recent reports have identified a population of progenitors, called neuromesodermal progenitors (NMPs), which reside in the posterior of developing vertebrate embryos (Henrique et al., 2015, Kimelman, 2016b). NMPs are competent to contribute to both the mesoderm and spinal cord during embryonic development (Garriock et al., 2015, Henrique et al., 2015, Tzouanacou et al., 2009). Extensive genetic and biochemical analysis determined that NMPs can be defined by the co-expression of low levels of the transcription factors Brachyury and Sox2 (Gouti et al., 2017, Koch et al.,

91 2017a, Turner et al., 2014a, Wymeersch et al., 2016). Also, the relative level of Fgf and

92 Wnt signaling activity regulate NMP cell fate decisions (i.e. differentiation into

93 mesodermal progenitors or neural progenitors) (Bouldin et al., 2015, Garriock et al.,

94 2015, Goto et al., 2017, Gouti et al., 2017, Gouti et al., 2015, Martin, 2016, Martin and

95 Kimelman, 2008, Turner et al., 2014a). Both Fgf and Wnt signaling are important

96 regulators of the NSC response to tail amputation, as inhibition of either Wnt or Fgf

97 blocks tail regeneration (Makanae et al., 2016, Ponomareva et al., 2015, Zhang et al.,

98 2000, Albors et al., 2015). Although the role of individual Fgf ligands in spinal cord

99 regeneration is relatively unknown, the expression of wnt5 has been elegantly shown to

100 be essential for orientated cell division and outgrowth of the spinal cord during whole tail

101 regeneration (Albors et al., 2015). However, the activity of these pathways after spinal

102 cord transection has not been well characterized. 
In this study we identify a role for miR-200a in stabilizing the NSC identity after

104 spinal cord transection in axolotl, by repressing expression of the mesodermal marker

105 brachyury. Furthermore, we uncovered other genes in the miR-200 pathway and provide

106 evidence that depending on the injury context, such as spinal cord lesion repair or spinal

107 cord outgrowth during tail regeneration, that miR-200a plays an important role in

108 determining the identity of NSCs in the spinal cord during the regenerative process.

\section{Results}

\section{Transcriptional profiling identifies conserved miR-200a targets in homeostatic}

113 versus regenerating spinal cords

114 We previously identified miR-200a as a key microRNA (miRNA) that inhibits c-jun

115 expression in neural stem cells in the spinal cord after injury, and hence plays an

116 important role in preventing reactive gliosis and promoting a pro-regenerative

117 response(Sabin et al., 2019). Additional RNA sequencing (RNA-seq) on uninjured and 4

118 days post injury spinal cord tissue electroporated with a control or specific, antisense

119 miR-200a inhibitor identified other targets of miR-200a in axolotl spinal cord (Fig. 1A,

120 Table S1). During normal regeneration at 4 days post injury there were 1,163 genes that

121 are differentially expressed (Log2 fold change $\geq 2$-fold, $p \leq 0.05$ ) compared to uninjured

122 spinal cords. Inhibition of miR-200a in the uninjured spinal cord resulted in 6,235

123 transcripts with a greater than 2-fold differential expression compared to control

124 uninjured spinal cords. Interestingly, of the 6,235 differentially expressed genes, only

1252,760 were up-regulated (Fig.1A, Fig. S1, Table S1). We used GOrilla analysis to

126 identify gene ontology (GO) terms for the subset of genes that were significantly up-

127 regulated after miR-200a inhibition. GO terms involved with translation, RNA

128 metabolism, peptide metabolism, and translation initiation were significantly enriched in

129 this gene set $\left(p \leq 10^{-24}\right)$ (Fig.S1). Interestingly, the 3,475 genes that were significantly

130 down-regulated in uninjured spinal cords after miR-200a inhibition were enriched for GO

131 terms involved with organismal development, developmental process, cellular

132 differentiation, and signaling ( $p \leq 10^{-22}$ ) (Fig. S1).

133 Analysis of differentially expressed genes at 4 days post injury after miR-200a

134 inhibition identified a total of 1,007 genes that were differentially expressed compared to

135 control spinal cords. This is a much smaller gene set and suggests that there is a higher

136 specificity to genes affected by miR-200a during spinal cord regeneration. A total of 797 
137 genes were up-regulated and 210 genes were down-regulated after miR-200a inhibition

138 (Fig. S1). Genes that were up-regulated were enriched for GO terms involved with

139 nucleic acid metabolism, specifically RNA metabolism, and protein localization ( $\mathrm{p} \leq 10^{-6}$ )

140 (Fig. S1). Interestingly, the top GO terms enriched in down-regulated genes were

141 involved with nervous system processes, specifically synaptic signaling and chemical

142 synaptic signaling, as well as nervous system development $\left(p \leq 10^{-6}\right)$.

143 Taking a more targeted gene-level approach, we generated a heat map of the 30

144 most significantly up-regulated and down-regulated genes in all four conditions (Fig.1C).

145 Consistent with the GO analysis, genes involved in RNA processing, nucleic acid

146 metabolism, and protein targeting were among the most up-regulated genes in our data

147 set (tdrd9, acap1, eme1, zfp324b). Similarly, genes involved with neurotransmitter

148 transport, neuronal polarization, neurotrophin signaling, and neuronal differentiation

149 were among the most down-regulated genes (slc6a6, brsk1, slc6a14, arhgap8,

150 neurog1). Surprisingly, the transcription factor brachyury $(T)$ was among one of the most

151 up-regulated genes at 4 days post injury in response to miR-200a inhibition (Fig.1C). In

1524 days post injury controls, brachyury was not up-regulated in response to injury, the

153 RNA seq transcripts per million (TPM) values on Control uninjured were 0.782 TPM,

154 versus 4 dpi post injury 0.92 TPM, show no significant increase (Table S1). However,

155 inhibition of miR-200a in uninjured spinal cords led to a 2-fold increase in brachyury

156 expression (2.236 TPM), while the combination of miR-200a inhibition during injury led to

157 a highly significant 7-fold increase in its mRNA levels (5.8 TPM, Table S1).

158 We used quantitative RT-PCR (qRT-PCR) to verify genes of interest revealed by

159 RNA-seq, this approach confirmed that brachyury is detectable at very low levels in

160 uninjured and control 4 days post injury spinal cords but is significantly up-regulated

161 after miR-200a inhibition in 4 days post injury spinal cords (Fig.1D). This is an intriguing

162 finding as brachyury is considered a classical marker of mesodermal tissue and was

163 originally thought to be absent from in the nervous system. However, more recent

164 research has identified a bipotent cell population in development, in which some spinal

165 cord neural progenitor cells are developmentally derived from Sox2/Brachyury ${ }^{+}$

166 neuromesodermal progenitors (NMPs) (Garriock et al., 2015, Tzouanacou et al., 2009,

167 Wymeersch et al., 2016). In the axolotl, the bona fide stem cells that line the central

168 canal are identified by the expression of the glial cell marker GFAP and the neural stem

169 cell marker Sox2. These $\mathrm{GFAP}^{+} / \mathrm{Sox}^{+}$cells respond to the injury, divide, migrate and

170 repair a lesion in the spinal cord, or regenerate lost cells and tissues in the context of 
171 whole tail regeneration (Sabin et al., 2015a, Fei et al., 2014b, Echeverri and Tanaka,

172 2002, Echeverri and Tanaka, 2003a, McHedlishvili et al., 2007, McHedlishvili et al.,

173 2012). Given that NMPs and axolotl glial cells both express Sox2 and that sox2 is a miR-

174 200a target during mouse brain development (Peng et al., 2012), we assayed sox2

175 transcript abundance. Interestingly, while sox2 is slightly up-regulated in control 4 days

176 post injury compared to uninjured spinal cords, sox2 expression did not increase in miR-

$177200 a$ inhibitor treated spinal cords. Instead, the sox2 transcript abundance remains near

178 uninjured homeostatic levels (Fig.1D). This observation suggests that axolotl sox2 is not

179 a direct target of miR-200a as it is in mammals (Pandey et al., 2015, Peng et al., 2012,

180 Wang et al., 2013).

$181 \quad$ To identify the cells that express brachyury in the 4 days post injury spinal cord

182 after miR-200a inhibition, in situ hybridization was used. In situ hybridization determined

183 that cells lining the central canal are brachyury ${ }^{+}$after miR-200a inhibition (Fig.1Evii), and

184 importantly, this is the same population of cells that express sox2 (Fig.1Evi, viii) .

185 Collectively, this data indicates that miR-200a inhibition leads to increased brachyury

186 expression in stem cells in the axolotl spinal cord. Although these progenitor cells have

187 been traditionally thought of as NSCs due to their expression of the classical NSC

188 marker sox2, they also express low levels of the mesodermal marker brachyury

189 (Fig.1D), suggesting that they are in fact a population of bipotent stem cells and may in

190 fact have broader differentiation potential.

192 Inhibition of miR-200a leads to changes in cell fate after spinal cord injury

193 To determine if miR-200a inhibition and subsequent upregulation of the mesodermal

194 marker brachyury leads to changes in the number of NSC in the regenerating spinal

195 cord, we quantified the number of Sox $2^{+}$cells in control versus inhibitor treated animals

196 (Fig.2A, B). Previous work has shown that after spinal cord injury the cells that are

197 activated to partake in the regeneration process lie within $500 \mu \mathrm{m}$ of the injury site.

198 However, we detected no significant difference in the total number of Sox $2^{+}$cells $500 \mu \mathrm{m}$

199 rostral or caudal of the injury site (Fig.2A, B). During the normal regenerative process in

200 the spinal cord, the Sox $2^{+}$stem cells will replenish the $\mathrm{GFAP}^{+}$cell population and

201 differentiate into new neurons (Albors et al., 2015, Echeverri and Tanaka, 2002,

202 Echeverri and Tanaka, 2003a, McHedlishvili et al., 2007, McHedlishvili et al., 2012). To

203 determine if the number of newborn neurons is affected by miR-200a inhibition we

204 quantified the number of $\mathrm{NeuN}$ and EDU ${ }^{+}$cells $500 \mu \mathrm{m}$ rostral and caudal to the injury 
205 site. We found that overall, significantly fewer $\mathrm{NeuN}^{+} / \mathrm{EdU}^{+}$cells were found in the miR-

206 200a inhibitor animals (Fig. 2C, D). Collectively, these data demonstrated that the total

207 number of the Sox $2^{+}$spinal cord stem cells is relatively the same in control versus miR-

208200 a inhibited animals, but less $\mathrm{NeuN}^{+}$cells are found in the inhibitor treated animals.

209 These findings suggest that either more cells remain in a progenitor-like state, or the

210 expression of brachyury in the miR-200a inhibitor treated animals changes the fate of

211 the cells. To address this question, we used in vivo cell tracking to determine the fate of

212 these cells during regeneration of the lesioned spinal cord. We have previously tracked

213 the fate of $\mathrm{GFAP}^{+}$spinal cord stem cells during regeneration of the lesioned spinal cord

214 and found that these cells proliferate and migrate to replace the portion of injured neural

215 tube, and that this is a bidirectional process (Sabin et al., 2015a). The same technique

216 was used in these studies, the axolotl GFAP promoter driving expression of a

217 fluorescent protein was injected into the lumen of the spinal cord, the animals were

218 electroporated to label small groups of cells. The miR-200a inhibitor was injected into

219 animals with fluorescently labelled cells and then the spinal cord ablation was performed

220 (Sabin et al., 2019). The animals were imaged every 3-days over a two-week time

221 period. In the control labelled animals, we found the cells behaved as we had previously

222 described, the labeled cells proliferated and partook in repair of the neural tube,

223 replenished the endogenous stem cell population, and differentiated to replace lost

224 neurons (Fig.3 A-D), consistent with our previous work (Sabin et al., 2015). In contrast,

225 in the miR-200a inhibitor treated animals although the cells proliferated and partook in

226 repair of the lesioned spinal cord, we also discovered that the cells exited from the spinal

227 cord and differentiated into muscle cells. The labelled cells which started in the spinal

228 cord where always found in the muscle layer adjacent or directly above the spinal cord

229 (Fig.3I, J). In all miR-200a inhibitor treated animals we observed at least 1 muscle fiber

230 being formed in all animals $(n=25)$, although in some animal's multiple fibers were seen.

231 Additionally, in inhibitor and control animals' some cells differentiated into neurons and

232 remained within the neural tube to give rise to new glial cells (data not shown). This data

233 suggests that miR-200a represses brachyury in sox $2^{+}$spinal cord stem cells, maintaining

234 the cells in neural primed state. Inhibition of miR-200a in these cells results in the co-

235 expression of neural (sox2) and mesoderm (brachyury) markers, converting the cells into

236 a bipotent progenitor population capable of making both neural and mesodermal cells.

\section{Molecular regulation of progenitor cells by miR-200a}


Our data strongly indicate that inhibition of miR-200a leads to the expression of

240 brachyury in stem cells within the axolotl spinal cord (Fig. 1D,). However, the signaling

241 pathway(s) upstream of brachyury expression were not known. As a first step we first

242 tested whether miR-200a could directly repress brachyury expression. The axolotl

243 brachyury 3' untranslated region (UTR) contains three miR-200a seed sequences, this

244 indicates that miR-200a could directly regulate brachyury expression. Consistent with

245 this hypothesis, co-transfection of B35 neural cells with a brachyury 3' UTR luciferase

246 reporter and miR-200a mimic led to decreased luciferase activity compared to the

247 control mimic (Fig. S2A). This finding confirmed that miR-200a directly represses

248 brachyury expression in axolotl spinal cord stem cells in homeostatic conditions and

249 during normal regeneration.

250 During normal spinal cord regeneration in the context of a tail amputation model

251 it has been found that wnt genes are re-expressed in the caudal $500 \mu \mathrm{m}$ of the

252 outgrowing spinal cord and are necessary for this outgrowth (Albors et al., 2015).Further

253 studies have shown that inhibition of all Wnt or Fgf signaling after tail amputation

254 abolished regenerative outgrowth, suggesting both are necessary for spinal cord and tail

255 regeneration (Ponomareva et al., 2015). As both Fgf and Wnt signaling regulate cell fate

256 decisions of brachyury ${ }^{+} /$sox $^{+}$NMPs during development, we first tested whether Fgf

257 signaling could be affected by miR-200a inhibition during regeneration. We assayed for

258 expression of $f g f 8$ and $f g f 10$ by $q R T-P C R$ on isolated spinal cord tissue. Fgf8 expression

259 was slightly down-regulated at 4 days post injury after miR-200a inhibition compared to

260 uninjured spinal cords (Fig.4A), while fgf10 expression was significantly up-regulated

261 after miR-200a inhibition in 4 days post injury spinal cords compared to controls

262 (Fig.4A). This finding is consistent with the idea that miR-200a inhibition could lead to an

263 increase in fgfligand expression in regenerating spinal cords. However, given that Wnt

264 signaling directly regulates Brachyury expression (Arnold et al., 2000, Yamaguchi et al.,

265 1999) and NMP cell fate decisions (Bouldin et al., 2015, Garriock et al., 2015, Martin,

266 2016, Martin and Kimelman, 2008), we wanted to further examine the role of Wnt

267 signaling.

268 The expression levels of $w n t 3 a$, wnt5a, wnt8a were quantified using qRT-PCR

269 (Fig. 4B). Both wnt3a and wnt8 transcript levels were not significantly altered in the

270 inhibitor treated animals compared to controls. However, we did detect a significant

271 difference in wnt5a levels. In 4 day post injury controls, wnt5a was up-regulated after

272 injury, although this change in expression was not found in the miR-200a inhibitor 
273 treated animals. To further verify the qRT-PCR results for fgf and wnt genes we

274 performed fluorescent in situs for fgf10 and wnt5a in control and miR-200a inhibitor

275 treated regenerating animals. This confirmed that indeed fgf10 transcript levels are up-

276 regulated in cells within the spinal cord in comparison to the control regenerating

277 animals (Fig.4C, D). Additionally, wnt5a transcript levels were down-regulated in cells

278 within the spinal cord in comparison to controls (Fig.4C, D). Although here we see only

279 changes in wnt5a expression, a Wnt which is known to play an important role in

280 regeneration (Albors et al., 2015), there are many additional Wnt ligands, therefore Wnt

281 signaling activity could still be affected by miR-200a inhibition. To establish a baseline

282 for Wnt signaling activity after spinal cord injury we assayed lef1 expression, which is a

283 direct transcriptional target downstream of Wnt signaling (Filali et al., 2002). Lef1

284 expression was significantly up-regulated in control 4 days post injury compared to

285 uninjured spinal cords (Fig. S3A), indicating a potential increase in Wnt signaling after

286 injury. Remarkably, lef1 expression was significantly up-regulated even further after miR-

$287200 a$ inhibition in 4 days post injury compared to control regenerating spinal cords (Fig.

288 S3A). Collectively, these data indicate that miR-200a inhibition could result in increased

289 Wnt signaling, potentially independent of changes in wnt ligand expression.

\section{miR-200a modulates Wnt signaling activity by directly targeting $\beta$-catenin}

292 While miR-200a inhibition could lead to increased Wnt signaling, it was not clear

293 how this was occurring. During tumor progression, miR-200a inhibits the epithelial-to -

294 mesenchymal transition subsequently blocking tumor cell metastasis (Su et al., 2012,

295 Zaravinos, 2015). This is partially achieved through the direct repression of $\beta$-catenin by

296 miR-200a, resulting in decreased Wnt signaling (Su et al., 2012). We did not observe a

297 significant up-regulation of specific wnt ligand expression after miR-200a inhibition in the

298 spinal cord cells (Fig. 4B). However, as determined by lef1 expression, miR-200a

299 inhibition could lead to increased Wnt signaling (Fig. S3A). Therefore, we hypothesized

300 that miR-200a might regulate Wnt signaling by targeting $\beta$-catenin. To test our

301 hypothesis, we first assayed for changes in $\beta$-catenin transcript abundance (ctnnb1).

302 qRT-PCR analysis confirmed that after injury in control 4 days post injury spinal cords,

303 there is an increase in ctnnb1 abundance compared to uninjured spinal cords, similar to

304 what we observed for lef1 (Fig. S3A). There is a slight increase of ctnnb1 transcript

305 levels after miR-200a inhibition compared to control 4 days post injury spinal cords (Fig.

306 S3A), indicating $\beta$-catenin could be a direct target of miR-200a in axolotl. 
To determine whether miR-200a could target axolotl $\beta$-catenin, we cloned the ctnnb1 3' UTR and identified two miR-200a seed sequences. We subcloned the ctnnb1 3' UTR into a luciferase reporter and co-transfected cells with a control mimic or miR200a specific mimic. There was decreased luciferase activity in miR-200a mimic transfected cells compared to control, suggesting that miR-200a could regulate $\beta$-catenin

312 expression (Fig. S3B). To confirm that the decrease in luciferase activity is due to direct

313 regulation by miR-200a, we mutated both seed sequences in the ctnnb1 3' UTR and

314 repeated the luciferase experiments. Mutation of the miR-200a seed sequences

315 completely alleviated the repression, confirming that axolotl $\beta$-catenin is a direct target of

316 miR-200a, similar to mammals (Fig. S3B).

Taken together, these data are consistent with the idea that miR-200a could

318 modulate Wnt signaling through the direct regulation of $\beta$-catenin transcript levels.

319 Inhibition of miR-200a leads to increased lef1 expression, which is indicative of

320 increased Wnt signaling. Increased levels of Wnt signaling may contribute to the

321 increased brachyury expression and changes in fgf10 levels in axolotl stem cells after

322 spinal cord lesion.

\section{The role of spinal cord stem cells in spinal cord injury versus tail regeneration}

325 We have shown that when a lesion occurs in the axolotl spinal cord the glial cells

326 adjacent to the injury site respond to the injury cue and proceed to behave like NSCs;

327 they divide, migrate, self-renew and replace lost neurons. However, previous work has

328 shown that during spinal cord regeneration after amputation, rather than injury, these

329 glial cells can transdifferentiate and give rise to cells of both the ectodermal and

330 mesodermal lineage (Echeverri and Tanaka, 2002, McHedlishvili et al., 2007). We next

331 examined the expression of brachyury in the context of whole tail regeneration and

332 discovered that brachyury is expressed in the sox $2^{+}$stem cells of the spinal cord $500 \mu \mathrm{m}$

333 adjacent to the injury site at 7-days post amputation (Fig. 5). To determine if this is an

334 attribute of the larval animals only, we also examined regenerating tail tissue from 2-year

335 old adult animals and found that in response to tail amputation that these progenitor cells

336 in the adult spinal cord indeed co-express brachyury and sox2 during tail regeneration in

337 adult (Fig. 5) and larval animals (Fig.S4). These data suggest that during the

338 regenerative process the cells lining the central canal determine what tissue types need

339 to be restored. When only a small portion of the neural tube must be regenerated

340 following injury, the progenitor cells adopt a neural stem cell state to successfully 
341 regenerate the spinal cord. During whole tail regeneration following amputation when

342 multiple tissue lineages must be regenerated, these cells within the spinal cord become

343 bipotent progenitors capable of making mesoderm and ectoderm (Fig.6).

344 Collectively, these experiments have shed light on the context dependent nature of

345 miRNA signaling during spinal cord lesion repair versus tail amputation and have

346 identified new signaling pathways that regulate progenitor cell fate during axolotl spinal

347 cord regeneration.

\section{Discussion}

The current study has identified miR-200a as a regulator of stem cell fate in the regenerating axolotl spinal cord. GO term analysis of genes down-regulated in the

353 uninjured and 4 days post injury spinal cord after miR-200a inhibition showed that these

354 genes were involved with nervous system development, organismal development,

355 synaptic signaling, and cellular differentiation (Fig.1, Fig.S1). Specifically, genes

356 involved with neuronal differentiation (neurog1, neuroD4) and neuronal processes like

357 synaptic transmission (CHRNB1, GABRA4) and neurotransmitter uptake (SLC6A6,

358 SLC18A3, SLC6A14) were down-regulated (Fig.1, Fig. S1). This suggests that miR-

359200 a normally functions to promote NSC identity. This is consistent with multiple reports

360 across various species that inhibition of miR-200a and other miR-200 family members

361 results in the loss of neural progenitor identity and precocious neuronal or glial

362 differentiation (Buller et al., 2012, Choi et al., 2008, Morante et al., 2013, Peng et al.,

363 2012, Trumbach and Prakash, 2015, Vallejo et al., 2011). However, we have found that

364 in the axolotl spinal cord that even in uninjured conditions in larval or adult axolotls, the

365 cells lining the central canal in fact express low levels brachyury and sox2, the classical

366 markers of mesoderm and neural stem cells (Fig.1D, Fig.5). These cells may represent

367 a bipotent progenitor cell population and our data suggests that increased levels of

368 brachyury are necessary for a progenitor to make the decision to exit the spinal cord and

369 become a cell type of mesodermal origin (Fig.6).

$370 \quad$ During embryonic development in multiple species a small population of cells that

371 co-express Sox2 and Brachyury have been identified and are now called

372 neuromesodermal progenitor cells (Gouti et al., 2014, Henrique et al., 2015, Jurberg et

373 al., 2013, Kimelman, 2016b, Taniguchi et al., 2017, Tsakiridis et al., 2014, Tsakiridis and

374 Wilson, 2015, Turner et al., 2014b, Tzouanacou et al., 2009). Neuromesodermal 
375 progenitor cell commitment to the neural lineage is partially determined by the relative

376 levels of Sox2 compared to Brachyury, given that the two transcription factors function to

377 antagonize one another (Koch et al., 2017a) and by the respective levels of fgf versus

378 wnt that the progenitor cells encounter (refs). During axolotl development to date a

379 definitive population of neuromesodermal progenitors has not been defined, however

380 work published by Taniguichi et al has shown that a posterior region of the axolotl neural

381 plate is positive for brachyury and sox2 and this region gives rise to mesoderm during

382 development (Taniguchi et al., 2017). This finding is consistent with the idea that the

383 axolotl may also have a bipotent progenitor pool of cells established during early

384 development, however more work is needed, especially lineage tracing to establish if

385 these cells behave similar to what is seen in other species like chick, mouse and

386 zebrafish. Our results here showing that by qRT-PCR and RNAscope in situs that

387 brachyury and sox2 are detected in the progenitor cells of the spinal cord in both larval

388 and adult axolotls would suggest that axolotls retain a population of cells in the spinal

389 cord throughout life that are bipotent. Work from McHedlishvili et al previously showed

390 that adult axolotl retains expression of embryonic markers of dorsal/ventral patterning

391 like pax7, pax6 and shh genes that are not expressed in adult mammalian spinal cord

392 (McHedlishvili et al., 2007). They additionally showed that like earlier lineage tracing

393 work in axolotl, cells from the spinal cord do in fact migrate out and form a range of other

394 cell types including blood vessels, skin, cartilage, and muscle cells. Overall, these

395 bodies of work indicate that the cells in the axolotl spinal cord retain a multi-potent

396 progenitor cell state and are capable to respond to injury cues which direct them towards

397 different cell fates as needed. Very early work on tail regeneration in salamanders had

398 already hinted that the terminal vesicle structure formed at the growing end of the spinal

399 cord during tail regeneration is an area of epithelial to mesenchymal transition where

400 cells delaminate from the neural tube and exit to contribute to regeneration of

401 surrounding tissues of other developmental lineages (Benraiss et al., 1997, Egar and

402 Singer, 1972, O'Hara et al., 1992). Our data now gives molecular insights into the

403 identity of these cells. We found that miR-200a inhibited cells increase levels of

404 brachyury and then these cells during regeneration of a spinal cord lesion will form

405 muscle which is not observed in control regenerating lesions. However, we have not

406 observed these cells to form cartilage, skin, fin mesenchyme of any other cell type. We

407 cannot rule out that they have this potential, but the lineage tracing is limited as the

408 fluorescent protein expression is driven by the GFAP promoter, we expect this promoter 
409 is turned off as the cells differentiate and as we can only image very 3 days, we may in

410 fact miss some differentiation events. We observed in all animals where miR-200a is

411 inhibited that at least one muscle fiber is formed from the labelled cells, however, again

412 we may be missing some differentiation events due to the limitations of our labelling

413 technique.

414 It is still not clear whether Brachyury directly regulates Sox2 levels in the regenerating

415 axolotl spinal cord or whether it is via an indirect mechanism. Work from other labs in

416 other research organisms has indicated that Brachyury and Sox2 can have a mutually

417 repressive relationship (Kimelman, 2016a, Koch et al., 2017b, Martin, 2016). We have

418 shown that miR-200a directly regulates brachyury and $\beta$-catenin via seed sequences in

419 the 3'UTR of these genes. When miR-200a is inhibited in the spinal cord cells, brachyury

420 is expressed at higher levels in these cells but fgf and wnt levels are also perturbed.

421 Work in development on NMP's has shown that feedback loops exist between

422 brachyury, fgf and wnt genes, and hence a complex signaling network may exist that is

423 driven by specific levels of certain regulators in these cells at particular times. An

424 additional level of complexity is the fact that Wnt is a secreted protein and although we

425 see downregulation of it within the progenitor cells in the spinal cord, we also see that

426 cells outside the spinal cord express wnt (Fig.4) and therefore the progenitor cells may

427 also be influenced by external gradients of Wnt protein.

428 During development, Wnt and Fgf signaling tightly regulate neuromesodermal cell fate

429 decisions (Goto et al., 2017, Gouti et al., 2017, Gouti et al., 2015, Martin, 2016) and both

430 genes are known to play important roles in regeneration (Sun et al., 2002, Wilson et al.,

431 2000, Zhang et al., 2000, Zhang et al., 2002b, Caubit et al., 1997, Ghosh et al., 2008,

432 Lin G, 2008, Stoick-Cooper et al., 2007, Tanaka and Weidinger, 2008, Wehner et al.,

433 2017, Zakany and Duboule, 1993). Canonical Wnt signaling is crucial for radial glial cell

434 proliferation during neural tube development (Shtutman et al., 1999) and spinal cord

435 regeneration in zebrafish (Briona et al., 2015). Therefore, it is not surprising to see a

436 potential increase in Wnt signaling during spinal cord regeneration in axolotl. However, it

437 is interesting that miR-200a does not regulate expression of wnt ligands, but instead

438 regulates $\beta$-catenin levels (Fig. S3). This is reminiscent to the role of miR-200a in

439 inhibiting EMT by repressing $\beta$-catenin and canonical Wnt signaling (Su et al., 2012,

440 Zaravinos, 2015). The increase in ctnnb1 levels after miR-200a inhibition is not

441 statistically significant, however slight changes in transcript abundance can have

442 profound effects on protein levels (Schwanhausser et al., 2011). Therefore, a modest 
443 increase in transcript abundance could represent a biologically significant increase in $\beta$ -

444 catenin protein levels.

445 The signals that inform injured cells what tissue must be replaced remain a mystery.

446 Here we show that glial cells in the spinal cord appear to sense the difference between a

447 lesion of the spinal cord that primarily needs replacement of neural stem cell and

448 neurons, versus regeneration in the context of whole tail regeneration where cells of

449 multiple developmental germ layer origin must be regenerated. Interestingly we find that

450 cells of both the larval and adult tail regenerate bipotent progenitors that express

451 brachyury and sox2 in response to tail amputation, suggesting that the presence of

452 these bipotent progenitors is not only a hallmark of embryonic development, but rather a

453 stem cell population that is maintained in the animals specifically for regeneration. In the

454 future it will be important to determine if all cells in the spinal cord have this potential or

455 whether there are sub-populations of stem cells present in the axolotl spinal cord.

Materials and Methods

Animal Handling and Spinal Cord Injury

$464 \quad$ All axolotls used in these experiments were obtained and bred at the University 465 of Minnesota or the Marine Biological Laboratory in accordance with IACUAC

466 regulations. Prior to all in vivo experiments, animals $(3-5 \mathrm{~cm})$ were anesthetized in $0.01 \%$

467 p-amino benzocaine (Sigma). Spinal cord ablations were performed as previously

468 described (Diaz Quiroz et al., 2014,Sabin et al., 2015a). Briefly, a 26-gage needle was

469 used to clear away skin and muscle to expose the spinal cord 6-10 muscle bundles

470 caudle to the cloaca. Then, using the needle, a segment of spinal cord 1 muscle bundle

471 thick, approximately $500 \mu \mathrm{m}$, was removed. Animals were placed in cups and monitored

472 for the duration of the experiments.

473

474 Immunohistochemistry and EdU

475 Tissue was harvested and fixed in fresh $4 \%$ paraformaldehyde (Sigma) overnight

476 at $4^{\circ} \mathrm{C}$. Then tails were washed three times in phosphate buffered saline $+0.1 \%$ Tween 
47720 (PBSTw). Next the tails were incubated in a 50:50 solution of PBSTw and 30\%

478 sucrose. Finally, tails were transferred to $30 \%$ sucrose solution and allowed to

479 equilibrate overnight at $4^{\circ} \mathrm{C}$. The next day samples were embedded for cross-sectioning

480 in TissueTek (Sakura) and stored at $-20^{\circ} \mathrm{C}$.

$481 \quad$ For EdU staining, animals were injected intraperitoneal with EdU at a

482 concentration of $0.5 \mu \mathrm{g} / \mu \mathrm{L}$ in PBS+1\% Fast Green at 5 and 7 -days post injury then

483 harvested at 14-days post injury. The tissue was processed for sectioning as described

484 above and stained using the Click-iT EdU Imaging Kit (Invitrogen) according to the

485 manufacturer's instructions.

486 After staining for EdU, samples were processed for immunohistochemical

487 analysis using either anti-Sox2 (Abcam) or anti-NeuN (Chemicon) primary antibodies as

488 previously described (Sabin et al., 2015a, Sabin et al., 2019). Briefly, slides were

489 subjected to a boiling citrate antigen retrieval step and then washed with PBSTw 3 times

490 for 5 minutes each. Samples were blocked (PBS+0.1\% Triton-X+2\% bovine serum

491 albumin $+2 \%$ goat serum) for an hour at room then incubated overnight at $4{ }^{\circ} \mathrm{C}$ in primary

492 antibodies diluted (1:100) in blocking buffer. The next day, slides were washed 4 times

493 with PBSTw and then incubated with secondary antibody (Invitrogen) diluted in blocking

494 buffer (1:200) for 2 hours at room temp and cell nuclei were counterstained with 4',6-

495 diamidino-2-phenylindole (DAPI) $(1: 10,000)$. After secondary incubation the slides were

496 washed four times with PBSTw and mounted in Prolong Anti-fade mounting solution

497 (Invitrogen). All samples were imaged using an inverted Leica DMI 6000B fluorescent

498 microscope.

499 All images were generated using Fiji and cells were counted with the Cell

500 Counter plugin.

Quantitative Reverse Transcriptase Polymerase Chain Reaction

$503 \quad$ Injured spinal cords $500 \mu \mathrm{m}$ rostral and $300 \mu \mathrm{m}$ caudal to the lesion from 7-10

504 control or miR-200a inhibitor electroporated animals were micro dissected and pooled

505 for each biological replicate. Total RNA was isolated using Trizol (Invitrogen) according

506 to the manufacturer's instructions. Subsequent cDNA was synthesized from $1 \mu \mathrm{g}$ of

507 DNasel (NEB) treated RNA using either High Capacity cDNA Reverse Transcription kit

508 (Applied Biosystems) or miScript II RT kit (Qiagen). The qRT-PCR was carried out using

509 Light Cycler 480 SYBR Green I Master (Roche). MicroRNA qRT-PCR was carried out 
510 with custom designed primers to conserved miRNAs (Qiagen) and custom primers from

511 IDT were used to quantify axolotl mRNAs:

512

513 18S_F: CGGCTTAATTTGACTCAACACG

514 18S_R: TTAGCATGCCAGAGTCTCGTTC

515 brachyury_F: GAAGTATGTCAACGGGGAAT

516 brachyury_R: TTGTTGGTGAGCTTGACTTT

517 sox2_F: TTGTGCAAAATGTGTTTCCA

518 sox2_R: CATGTTGCTTCGCTTTAGAA

519 wnt3a_F: AAGACATGCTGGTGGTCTCA

520 wnt3a_R: CCCGTACGCATTCTTGACAG

521 wnt5a_F: ACCCTGTTCAAATCCCGGAG

522 wnt5a_R: GGTCTTTGCCCCTTCTCCAA

523 wnt8a_F: TTGCTGTCAAATCAACCATG

524 wnt8a_R: TGCCTATATCCCTGAACTCT

525 ctnnb1_F: ACCTTACAGATCAAAGCCAG

526 ctnnb1_R: GGACAAGTGTTCCAAGAAGA

527 lef1_F: GTCCCACAACTCCTACCACA

528 lef1_R: TAGGGGTCGCTGTTCACATT

529 fgf8_F: TTTGTCCTCTGCATGCAAGC

530 fgf8_R: GTCTCGGCTCCTTTAATGCG

531 fgf10_F: AAACTGAAGGAGCGGATGGA

532 fgf10_R: TCGATCTGCATGGGAAGGAA

534 Brachyury and Sox2 Probe Synthesis

535 Approximately 500bp fragments of axolotl brachyury and sox2 were PCR

536 amplified using OneStep PCR Kit (Qiagen) from RNA extracted from axolotl embryos at

537 various developmental stages using the following primers:

538

539 brachyury ISH For: CCCCAACGCCATGTACTCTT

540 brachyury ISH Rev: GGCCAAGCGATATAGGTGCT

542 sox2 ISH For: TGGCAATCAGGAAGAAAGTC

543 sox2 ISH Rev: GCAAATGACAGAGCCGAACT 
The resulting PCR fragments were gel purified using the Monarch Gel

546 Purification Kit (New England Biolabs) and TA cloned into pGEM-T Easy (Promega) then

547 transformed into DH5a competent E. coli (Invitrogen). Blue/White positive selection was

548 used to pick clones and recovered plasmids were sent for sequencing. Positive clones

549 were digested with the appropriate enzyme to linearize the plasmid and anti-sense

550 ribonucleoprobe synthesis was carried out using Sp6 or T7 RNA polymerase (New

551 England Biolabs)+DIG labeled UTP (Roche). Subsequent probes were cleaned up using

552 the RNA Clean Up kit (Qiagen) and resuspended in hybridization buffer.

\section{Fluorescent In situ Hybridization}

555 All RNAscope ${ }^{\circledR}$ in situ hybridization procedures were performed according to the

556 manufacturer's instructions (Advanced Cell Diagnostics). In brief, cryosections were

557 incubated in PBS for 10 minutes to remove the OCT, and then baked at $60^{\circ} \mathrm{C}$ for 30

558 minutes. The slides were next post-fixed in $4 \%$ paraformaldehyde for 15 minutes at $4{ }^{\circ} \mathrm{C}$,

559 and then dehydrated in a graded series of ethanol dilutions before being incubated in

560 absolute ethanol for 5 minutes. After briefly air-drying the slides for 5 minutes, sections

561 were next treated with hydrogen peroxide to quench endogenous peroxidase activity for

56210 minutes at room temperature. Next, samples were briefly washed in deionized water,

563 then incubated in target retrieval buffer at $90^{\circ} \mathrm{C}$ for 5 minutes. Following target retrieval,

564 the slides were rinsed in deionized water for 15 seconds and treated with absolute

565 ethanol for 3 minutes. Slides were next permeabilized in protease III for 30 minutes

566 before hybridization with RNAscope ${ }^{\circledR}$ probes at $40^{\circ} \mathrm{C}$ for 2 hours. Following

567 hybridization, sections were placed in 5x SSC overnight. The next day, sections were

568 incubated in Amp1 and Amp2 at $40^{\circ} \mathrm{C}$ for 30 minutes each, followed by Amp3 for 15

569 minutes. Next, slides were treated with HRP-C1 to detect brachyury or fgf10, followed by

570 a 30-minute incubation in Opal-690 fluorescent dye. After treatment with HRP blocking

571 buffer, samples were next incubated in HRP-C2 to detect either sox2 or wnt5a, followed

572 by a 30-minute incubation in Opal-570 dye. After an additional treatment with HRP

573 blocking buffer, slides were counterstained with DAPI and imaged using a Zeiss 780

574 Confocal Microscope.

575

$576 \quad$ Lineage Tracing 
577 Cells of the uninjured spinal cord were transfected with a construct containing a GFP or

578 tdTomato fluorescent protein under the control of the axolotl GFAP promoter. The cells

579 were injected and electroporated as previously described (Echeverri and Tanaka, 2003a,

580 Sabin et al., 2015a). One day after electroporation the animals were screened for

581 fluorescent cells. Positive animals were then injected with a control inhibitor or miR-200a

582 inhibitor and then a spinal cord lesion performed as described in (Sabin et al., 2019).

583 Animals were imaged every 3 days until the lesion site was no longer visible and the

584 animals regained motor and sensory function, typically 12-14 days post injury.

Cloning 3' Untranslated Regions for miRNA Luciferase Assays

For 3' UTR luciferase experiments, primers were designed to amplify the brachyury and $\beta$-catenin 3' UTR based off sequences obtained from axolotl-omics.org. All the 3' UTRs were amplified with a 5' Spel and 3' HindIII restriction site.

brachyury 3' UTR For 1 AGCACTAGTATGTGAAATGAGACTTCTAC brachyury 3' UTR Rev 1 TGCAAGCTTCTTATTCTTCCCATTTAACTTAAA

ctnnb1 3' UTR For 1 ATAACTAGTTTGTGTAATTTTTCTTAGCTGTCATAT ctnnb1 3' UTR Rev 1 ATCAAGCTTAATTGCTTTATAGTCTCTGCAGAT

ctnnb1 3' UTR SDM1 For AGTGCCTGATGAATTCAACCAAGCTGAG

603 The PCR fragments and pMiR Report (Life Technologies) were digested with Spel and

604 HindIII (NEB) and the fragments were ligated over night at $4^{\circ} \mathrm{C}$ with T4 DNA Ligase

605 (NEB) and heat shock transformed into DH5a competent E. coli (Promega).

To mutate the 3 miR-200a and 3 miR-200b sites in the axolotl Brachyury 3' UTR, 610 the manufacturer's instructions. 
612 miR-200a1 SDM: gactgctttctatggacacttttaatttctgaagataagctcccacccg

613 miR-200a2 SDM: cacacataaatctttcgtgctgaacaaattatgatccatgaaaccagtgcatcattt

614 miR-200a3 SDM: tccaatgtgtgtaatcctctcaattatcgcctctgcgtgtagaatgtc

615

616 miR-200b1 SDM: atgcattacaatgcattgtttctggacggcaatgaaagctgtgatgaaatatttaagat

617 miR-200b2 SDM: caccataagagacaataaatgcaccggaatactgtgatattgatgcctgcac

618 miR-200b3 SDM: gaatcattaccatgtatttatcaggccggaatattcaaaatgtgacttcctctgtga

\section{3' UTR luciferase experiments}

621 B35 neuroblastoma cells were plated in a 96 well plate (Celltreat Scientific

622 Products) at a concentration of $2.0 \times 10^{5}$ cells $/ \mathrm{mL}$ and allowed to adhere overnight. The

623 next day cells were co-transfected with the appropriate Luciferase 3' UTR reporter

624 plasmid, $\beta$-Galactosidase control, and 100nM of miR-200a, miR-200b, or control mimic

625 (Qiagen) per well using Lipofectamine 3000 (Invitrogen). After 48 hours luciferase

626 activity was determined using Dual Light Luciferase \& $\beta$-Galactosidase Reporter Gene

627 Assay System (Thermo) according to the manufacturer's protocol.

Pie Chart and Venn Diagram Generation

630 Pie charts were generated using previously published data (Sabin et al., 2019) to

631 represent the total number of differentially expressed genes in a given comparison using

632 Excel. Venn Diagrams were generated with Venny (v2.1.0) (Oliveros 2007-2015) and

633 saved as .csv files to be modified in Adobe Illustrator.

Gene Ontology (GO) Analysis

636 GO terms were determined using GOrilla (Eden et al., 2009). We used 2

637 unranked list of genes: a background list (all differentially expressed genes in our data

638 set) and a target list (genes that were differentially regulated in a given comparison).

639 Using this approach, GOrilla generated a list of enriched Biological Process GO terms

640 and we selected the top 9-13 terms with the lowest $p$-value and generated

641 representative bar graphs using Excel.

642

643 Calculation of the proportion and distribution of neural stem cells and newborn neurons 
644 The number of Sox2 ${ }^{+}$neural stem cells were counted in control and miR-200a

645 inhibitor spinal cords 2-weeks post injury. The proportion of Sox2 ${ }^{+}$neural stem cells was

646 calculated by dividing the total number of Sox ${ }^{+}$neural stem cells by the total number of

$647 \mathrm{DAPI}^{+}$spinal cord cells times 100. To analyze regenerative neurogenesis, control or

648 miR-200a inhibitor animals were injected with EdU at 5 and 7-days post injury, then tails

649 were harvested for cryosectioning at 14 days post injury. The proportion of newborn

650 neurons was determined by dividing the number of $\mathrm{NeuN}^{+} / \mathrm{EdU}^{+}$double positive neurons

651 by the total number of $\mathrm{NeuN}^{+}$neurons times 100 .

652 To visualize whether the proportion of Sox2 ${ }^{+}$neural stem cells changed rostral

653 and caudal to the injury site in control and miR-200a inhibitor spinal cords, we quantified

654 the average number of Sox $2^{+}$neural stem cells at a defined distance rostral and caudal

655 from the lesion. We divided that number by the average number of $\mathrm{DAPI}^{+}$spinal cord

656 cells at that same distance and then binned the vales from 3 adjacent serial sections

657 encompassing a region of $80 \mu \mathrm{m}$. We used the same method for graphing the distribution

658 of newborn neurons relative to the injury site.

Statistical Analyses

$661 \quad$ All results are presented as mean +/- s.d. unless otherwise stated. Analyses

662 were performed using Microsoft Excel or GraphPad Prism v8. Data set means were

663 compared using ANOVA for three or more tests with a Tukey test (for multiple

664 comparisons) or Dunnett test (to compare to a control mean). When two groups were

665 compared an unpaired $t$-test was used. When multiple comparisons were made using a

666 t-test, an adjusted p-value was determined using the two stage Benjamin, Krieger, and

667 Yekutieli procedue with a false discovery rate $<5 \%$. Differences between groups was

668 considered significant at three different levels ( $p$-values of ${ }^{*} \leq 0.05,{ }^{* *} \leq 0.01$ and

$\left.669^{* * *} \leq 0.001\right)$ and are indicated in the figure legends.

\section{Acknowledgements}

672 We thank Ricardo Zayas for feedback on the manuscript.

\section{Competing Interests}

675 The authors declare no competing financial interests.

\section{Funding}


678 KS has been supported by a NIH T32 GM113846 grant. KE is supported by a grant from 679 NICHD R01 HD092451, start-up funds from the MBL and funding from the Owens

680 Family Foundation.

681

682 Data Availability

683 The authors declare that all data supporting the findings of this study are available within 684 the article and its Supplementary Information files or from the corresponding author upon 685 reasonable request. The RNA seq data has been deposited in the public GEO database 686 with the accession number GSE122939.

687

688 
691 Figure 1. miR-200a inhibition during spinal cord injury leads to brachyury expression

692 axolotl in spinal cord stem cells. (A) RNA-Sequencing analysis identified a large subset

693 of differentially regulated genes following injury. The Vehn diagram compares the

694 number of overlapping differentially expressed genes between uninjured, 4 days post

695 injury control and miR-200a inhibitor treated samples. (B) Pie-chart showing the relative

696 portion of all transcripts that are differentially regulated. Regeneration specific transcripts

697 are defined as differentially expressed transcripts with a log2fc $>1$ or $<1$ and padj $<0.05$

698 between 4dpi control animals and 4dpi animals treated with mir-200a inhibitor that were

699 not differentially expressed in uninjured animals. (C) Log2fold change

700 heat map demonstrates the 30 most up- and down-regulated genes in uninjured and 4

701 days post injury control versus miR-200a inhibitor treated spinal cords. This analysis

702 revealed that the transcription factor brachyury $(T)$ is dramatically up-regulated after

703 miR-200a inhibition. (D) qRT-PCR analysis confirmed that miR-200a inhibition led to

704 increased brachyury expression and blocked the up-regulation of the neural stem cell

705 marker sox2 in 4 days post injury (dpi) spinal cords $(\mathrm{n}=3)$. (E) Fluorescent In situ

706 hybridization confirmed the qRT-PCR analysis and revealed miR-200a inhibition leads to

707 brachyury expression $(n=5)$ in spinal cord cells and a failure to up-regulate sox2

708 expression $(n=3) .{ }^{*} p \leq 0.05,{ }^{* *} p \leq 0.01$, ${ }^{* *} p \leq 0.001$, N.S. is not significant. Error bars represent \pm S.T.D. Scale bar $=50 \mu \mathrm{m}$.

711 Figure 2: Chronic miR-200a inhibition affects the birth of new neurons. Inhibition of miR200a for 2 weeks does not affect the (A) proportion or (B) distribution of Sox $2^{+}$stem cells in the spinal cord throughout the regeneration zone $(n=6)$. Inhibition of miR-200a for 2 weeks results in an smaller proportion of new born neurons compared to controls (C). (D) An increased proportion of new born neurons reside closer to the injury site while chronic miR-200a inhibition blocked this increase in new born neurons close to the injury site. $(n=6) .{ }^{*} p \leq 0.05,{ }^{* *} p \leq 0.01,{ }^{* * *} p \leq 0.001$, N.S. is not significant. Error bars represent $\pm S$.T.D.

Figure 3: miR-200a inhibited spinal cord cells form muscle during spinal cord lesion repair. The cells lining the central canal of the spinal cord were labelled using GFAP promoter driving GFP or tdTomato by injection and electroporation. Control cells were followed over a 14 day period and cells gave rise to new glial cells or neurons only $(A-F)$ $(n=20)$. Cells which were injected with the miR-200a inhibitor were followed in parallel over the same time period and were found to exit the spinal cord and give rise to muscle cells $(G-L) .(n=25)$. Scale bar $=50 \mu \mathrm{m}$.

Figure 4: miR-200a inhibition affects the expression of Wnt and FGF signaling ligands. (A) qRT-PCR analysis revealed fgf10, but not fgf8, was significantly up-regulated after miR-200a inhibition ( $n=3$ ). (B) qRT-PCR analysis showed that miR-200a inhibition differentially affects the expression of wnt5a, but not additional Wnt ligands (wnt3a, wnt8a; $\mathrm{n}=3$ ). (C) Fluorescent in situ hybridization in control (C) and miR-200a inhibitor treated (D) animals confirmed the qRT-PCR analysis, and demonstrates an increase in 
734 fgf10 expression and a down-regulation of wnt5a within stem cells in the spinal cord $735(n=6) .{ }^{*} p \leq 0.05,{ }^{* *} p \leq 0.01,{ }^{* * *} p \leq 0.001, N . S$. is not significant. Error bars represent

$736 \pm$ S.T.D. Scale bar $=50 \mu \mathrm{m}$.

Figure 5. Spinal cord amputation leads to brachyury expression in spinal cord stem cells. (Ai-iV) Fluorescent in situ hybridization revealed that sox2 is abundant within the uninjured adult spinal cord, while brachyury is absent $(n=2)$. (Bi-iv) At 7 days post amputation, brachyury was localized to spinal cord stem cells that share an overlapping expression pattern with sox2 $(n=2)$. Scale bar $=50 \mu \mathrm{m}$.

Figure 6. A proposed model for the role that miR-200a plays in different injury paradigms. When a lesion occurs in the spinal cord miR-200a levels remain high, which inhibits brachyury expression and modifies levels of $\beta$-catenin, potentially stabilizing a neural stem cell identity in the cells adjacent to the injury site. After spinal cord injury these cells replace neurons and glial only. In contrast, when the tail is amputated progenitor cells respond to injury cues and replace multiple cell types of different developmental origins. These cells in the spinal cord then up-regulate brachyury in the sox $2^{+}$stem cells of the spinal cord and direct these cells to proliferate and form cells of both ectodermal and mesodermal origin.

Supplementary Figure 1: miR-200a affects expression of common and unique gene sets in the uninjured and regenerating spinal cord. (A, B, C) Pie chart representation of the proportion of up-regulated (Red) or down-regulated (Blue) genes in (B) uninjured control compared to uninjured miR-200a inhibitor electroporated spinal cords or (A) 4 days post injury control compared to 4 days post injury miR-200a inhibitor electroporated spinal cords. (C). Pie chart illustrating the number of overlapping versus individual genes that are differentially regulated. (B-F) Gene Ontology terms enriched in gene specifically in $(B)$ control regenerating or $(E)$ genes common to all data sets or specific to uninjured

764 Supplementary Figure 2: Multiple miR-200 members directly regulate the brachyury 3'

765 UTR. (A) Co-transfection of B35 cells with a brachyury 3' luciferase reporter and a miR-

$766200 a(A)$ or miR-200b (B) mimic results in decreased luciferase activity compared to the

767 control mimic $(n=5)$. Mutation of all miR-200a seed sequences in the brachyury 3' UTR

768 alleviates this repression suggesting it is a direct target of miR-200 in axolotl $(n=4)$. **

$769 \mathrm{p} \leq 0.001$, N.S. is not significant. Error bars represent \pm S.T.D.

771 Supplementary Figure 3: miR-200a may regulate the expression of Wnt signaling

772 components. (A) qRT-PCR analysis revealed that miR-200a inhibition leads to increased 
773 expression of Wnt signaling transcriptional components lef1 and $\beta$-catenin. (B) Co-

774 transfection of B35 cells with a $\beta$-catenin 3' UTR luciferase reporter and a miR-200a

775 mimic leads to decreased luciferase activity compared to controls. Mutation of both miR-

776200 a seed sequences in the $\beta$-catenin 3' UTR alleviates this repression $(n=3)$. * $p \leq 0.05$,

$777^{* * *} p \leq 0.001$, N.S. is not significant. Error bars represent \pm S.T.D.

779 Supplementary Figure 4: brachyury is expressed in regenerating spinal cord stem cells

780 following amputation in larval animals. At 4 days post amputation (dpa) both sox2 (ii)

781 and brachyury (iii) are abundant in the spinal cord stem cells and share an overlapping

782 expression pattern (iv) $(\mathrm{n}=6)$. Scale bar $=50 \mathrm{~mm}$.

ALBORS, A. R., TAZAKI, A., ROST, F., NOWOSHILOW, S., CHARA, O. \& TANAKA, E. M. 2015. Planar cell polarity-mediated induction of neural stem cell expansion during axolotl spinal cord regeneration. eLife, 4, 1-29.

ARNOLD, S. J., STAPPERT, J., BAUER, A., KISPERT, A., HERRMANN, B. G. \& KEMLER, R. 2000. Brachyury is a target gene of the Wnt/beta-catenin signaling pathway. Mech Dev, 91, 249-58.

BENRAISS, A., ARSANTO, J. P., COULON, J. \& THOUVENY, Y. 1997. Neural CrestLike Cells Originate From the Spinal Cord During Tail Regeneration in Adult Amphibian Urodels. Developmental Dynamics, 209, 15-28.

BOULDIN, C. M., MANNING, A. J., PENG, Y. H., FARR, G. H., 3RD, HUNG, K. L., DONG, A. \& KIMELMAN, D. 2015. Wnt signaling and tbx16 form a bistable switch to commit bipotential progenitors to mesoderm. Development, 142, 2499507.

BRIONA, L. K., POULAIN, F. E., MOSIMANN, C. \& DORSKY, R. I. 2015. Wnt/sscatenin signaling is required for radial glial neurogenesis following spinal cord injury. Dev Biol, 403, 15-21.

BULLER, B., CHOPP, M., UENO, Y., ZHANG, L., ZHANG, R. L., MORRIS, D., ZHANG, Y. \& ZHANG, Z. G. 2012. Regulation of serum response factor by miRNA-200 and miRNA-9 modulates oligodendrocyte progenitor cell differentiation. Glia, 60, 1906-14.

BUTLER, E. G. \& WARD, M. B. 1965. Reconstitution of the spinal cord following ablation in urodele larvae. J Exp Zool, 160, 47-65. 
813 BUTLER, E. G. \& WARD, M. B. 1967. Reconstitution of the spinal cord after ablation in adult Triturus. Dev Biol, 15, 464-86.

CAUBIT, X., NICOLAS, S., SHI, D. L. \& LEPARCO, Y. 1997. Reactivation and graded axial expression pattern of Wnt-10a gene during early regeneration stages of adult tail in amphibian urodele Pleurodeles walt. Dev. Dyn., 208, 139-148.

CHOI, P. S., ZAKHARY, L., CHOI, W. Y., CARON, S., ALVAREZ-SAAVEDRA, E., MISKA, E. A., MCMANUS, M., HARFE, B., GIRALDEZ, A. J., HORVITZ, H. R., SCHIER, A. F. \& DULAC, C. 2008. Members of the miRNA-200 family regulate olfactory neurogenesis. Neuron, 57, 41-55.

CLARKE, J. D., ALEXANDER, R. \& HOLDER, N. 1988. Regeneration of descending axons in the spinal cord of the axolotl. Neurosci Lett, 89, 1-6.

DIAZ QUIROZ, J. F., TSAI, E., COYLE, M., SEHM, T. \& ECHEVERRI, K. 2014. Precise control of miR-125b levels is required to create a regeneration-permissive environment after spinal cord injury: a cross-species comparison between salamander and rat. Dis Model Mech, 7, 601-11.

ECHEVERRI, K. \& TANAKA, E. M. 2002. Ectoderm to mesoderm lineage switching during axolotl tail regeneration. Science, 298, 1993-6.

ECHEVERRI, K. \& TANAKA, E. M. 2003a. Electroporation as a tool to study in vivo spinal cord regeneration. Dev Dyn, 226, 418-25.

EDEN, E., NAVON, R., STEINFELD, I., LIPSON, D. \& YAKHINI, Z. 2009. GOrilla: a tool for discovery and visualization of enriched GO terms in ranked gene lists. BMC Bioinformatics, 10, 48.

EGAR, M. \& SINGER, M. 1972. The role of ependyma in spinal cord regeneration in the urodele, Triturus. Exp Neurol, 37, 422-30.

FEI, J.-F., KNAPP, D., SCHUEZ, M., MURAWALA, P., ZOU, Y., PAL SINGH, S., DRECHSEL, D. \& TANAKA, E. M. 2016. Tissue- and time-directed electroporation of CAS9 protein-gRNA complexes in vivo yields efficient multigene knockout for studying gene function in regeneration. Npj Regenerative Medicine, 1, 16002.

FEI, J. F., SCHUEZ, M., TAZAKI, A., TANIGUCHI, Y., ROENSCH, K. \& TANAKA, E. M. 2014a. CRISPR-mediated genomic deletion of Sox 2 in the axolotl shows a requirement in spinal cord neural stem cell amplification during tail regeneration. Stem Cell Reports, 3, 444-59.

FEI, J. F., SCHUEZ, M., TAZAKI, A., TANIGUCHI, Y., ROENSCH, K. \& TANAKA, E. M. 2014b. CRISPR-mediated genomic deletion of Sox2 in the axolotl shows a requirement in spinal cord neural stem cell amplification during tail regeneration. Stem Cell Reports, 3, 444-459.

FILALI, M., CHENG, N., ABBOTT, D., LEONTIEV, V. \& ENGELHARDT, J. F. 2002. Wnt-3A/beta-catenin signaling induces transcription from the LEF-1 promoter. $J$ Biol Chem, 277, 33398-410.

GARRIOCK, R. J., CHALAMALASETTY, R. B., KENNEDY, M. W., CANIZALES, L. C., LEWANDOSKI, M. \& YAMAGUCHI, T. P. 2015. Lineage tracing of neuromesodermal progenitors reveals novel Wnt-dependent roles in trunk progenitor cell maintenance and differentiation. Development, 142, 1628-38. 
GEARHART, M. D., ERICKSON, J. R., WALSH, A. \& ECHEVERRI, K. 2015. Identification of Conserved and Novel MicroRNAs during Tail Regeneration in the Mexican Axolotl. Int J Mol Sci, 16, 22046-61.

GHOSH, S., ROY, S., SEGUIN, C., BRYANT, S. V. \& GARDINER, D. M. 2008. Analysis of the expression and function of Wnt-5a and Wnt-5b in developing and regenerating axolotl (Ambystoma mexicanum) limbs. Dev Growth Differ, 50, 289-97.

GOTO, H., KIMMEY, S. C., ROW, R. H., MATUS, D. Q. \& MARTIN, B. L. 2017. FGF and canonical Wnt signaling cooperate to induce paraxial mesoderm from tailbud neuromesodermal progenitors through regulation of a two-step epithelial to mesenchymal transition. Development, 144, 1412-1424.

GOUTI, M., DELILE, J., STAMATAKI, D., WYMEERSCH, F. J., HUANG, Y., KLEINJUNG, J., WILSON, V. \& BRISCOE, J. 2017. A Gene Regulatory Network Balances Neural and Mesoderm Specification during Vertebrate Trunk Development. Dev Cell, 41, 243-261 e7.

GOUTI, M., METZIS, V. \& BRISCOE, J. 2015. The route to spinal cord cell types: a tale of signals and switches. Trends Genet, 31, 282-9.

GOUTI, M., TSAKIRIDIS, A., WYMEERSCH, F. J., HUANG, Y., KLEINJUNG, J., WILSON, V. \& BRISCOE, J. 2014. In vitro generation of neuromesodermal progenitors reveals distinct roles for wnt signalling in the specification of spinal cord and paraxial mesoderm identity. PLoS Biol, 12, e1001937.

HENRIQUE, D., ABRANCHES, E., VERRIER, L. \& STOREY, K. G. 2015. Neuromesodermal progenitors and the making of the spinal cord. Development, 142, 2864-75.

JURBERG, A. D., AIRES, R., VARELA-LASHERAS, I., NÓVOA, A. \& MALLO, M. 2013. Switching axial progenitors from producing trunk to tail tissues in vertebrate embryos. Dev Cell, 25, 451-62.

KARRES, J. S., HILGERS, V., CARRERA, I., TREISMAN, J. \& COHEN, S. M. 2007. The conserved microRNA miR-8 tunes atrophin levels to prevent neurodegeneration in Drosophila. Cell, 131, 136-45.

KIMELMAN, D. 2016a. A novel cold-sensitive mutant of ntla reveals temporal roles of brachyury in zebrafish. Dev Dyn, 245, 874-80.

KIMELMAN, D. 2016b. Tales of Tails (and Trunks): Forming the Posterior Body in Vertebrate Embryos. Curr Top Dev Biol, 116, 517-36.

KOCH, F., SCHOLZE, M., WITTLER, L., SCHIFFERL, D., SUDHEER, S., GROTE, P., TIMMERMANN, B., MACURA, K. \& HERRMANN, B. G. 2017a. Antagonistic Activities of Sox 2 and Brachyury Control the Fate Choice of NeuroMesodermal Progenitors. Dev Cell, 42, 514-526 e7.

KOCH, F., SCHOLZE, M., WITTLER, L., SCHIFFERL, D., SUDHEER, S., GROTE, P., TIMMERMANN, B., MACURA, K. \& HERRMANN, B. G. $2017 \mathrm{~b}$.

Antagonistic Activities of Sox 2 and Brachyury Control the Fate Choice of NeuroMesodermal Progenitors. Dev Cell, 42, 514-526.e7.

LEPP, A. C. \& CARLONE, R. L. 2014. RARbeta2 expression is induced by the downregulation of microRNA 133a during caudal spinal cord regeneration in the adult newt. Dev Dyn, 243, 1581-90. 
LIN G, S. J. M. 2008. Requirement for Wnt and FGF signaling in Xenopus tadpole tail regeneration. Dev Biol., 16, 323-35.

MAKANAE, A., MITOGAWA, K. \& SATOH, A. 2016. Cooperative inputs of Bmp and Fgf signaling induce tail regeneration in urodele amphibians. Dev Biol, 410, 4555.

MARTIN, B. L. 2016. Factors that coordinate mesoderm specification from neuromesodermal progenitors with segmentation during vertebrate axial extension. Semin Cell Dev Biol, 49, 59-67.

MARTIN, B. L. \& KIMELMAN, D. 2008. Regulation of canonical Wnt signaling by Brachyury is essential for posterior mesoderm formation. Dev Cell, 15, 121-33.

MCHEDLISHVILI, L., EPPERLEIN, H. H., TELZEROW, A. \& TANAKA, E. M. 2007. A clonal analysis of neural progenitors during axolotl spinal cord regeneration reveals evidence for both spatially restricted and multipotent progenitors. Development, 134, 2083-93.

MCHEDLISHVILI, L., MAZUROV, V., GRASSME, K. S., GOEHLER, K., ROBL, B., TAZAKI, A., ROENSCH, K., DUEMMLER, A. \& TANAKA, E. M. 2012. Reconstitution of the central and peripheral nervous system during salamander tail regeneration. Proc Natl Acad Sci U S A, 109, E2258-66.

MONAGHAN, J. R., WALKER, J. A., PAGE, R. B., PUTTA, S., BEACHY, C. K. \& VOSS, S. R. 2007. Early gene expression during natural spinal cord regeneration in the salamander Ambystoma mexicanum. J Neurochem, 101, 27-40.

MORANTE, J., VALLEJO, D. M., DESPLAN, C. \& DOMINGUEZ, M. 2013. Conserved miR-8/miR-200 defines a glial niche that controls neuroepithelial expansion and neuroblast transition. Dev Cell, 27, 174-187.

O'HARA, C. M., EGAR, M. W. \& CHERNOFF, E. A. 1992. Reorganization of the ependyma during axolotl spinal cord regeneration: changes in intermediate filament and fibronectin expression. Dev Dyn, 193, 103-15.

PANDEY, A., SINGH, P., JAUHARI, A., SINGH, T., KHAN, F., PANT, A. B., PARMAR, D. \& YADAV, S. 2015. Critical role of the miR-200 family in regulating differentiation and proliferation of neurons. J Neurochem, 133, 640-52.

PENG, C., LI, N., NG, Y. K., ZHANG, J., MEIER, F., THEIS, F. J., MERKENSCHLAGER, M., CHEN, W., WURST, W. \& PRAKASH, N. 2012. A unilateral negative feedback loop between miR-200 microRNAs and Sox2/E2F3 controls neural progenitor cell-cycle exit and differentiation. J Neurosci, 32, 13292-308.

PIATT, J. 1955. Regeneration of the Spinal Cord in the Salamander. Journal of Experimental Zoology, 129, 177-207.

PONOMAREVA, L. V., ATHIPPOZHY, A., THORSON, J. S. \& VOSS, S. R. 2015. Using Ambystoma mexicanum (Mexican axolotl) embryos, chemical genetics, and microarray analysis to identify signaling pathways associated with tissue regeneration. Comp Biochem Physiol C Toxicol Pharmacol, 178, 128-135.

RODRIGO ALBORS, A., TAZAKI, A., ROST, F., NOWOSHILOW, S., CHARA, O. \& TANAKA, E. M. 2015. Planar cell polarity-mediated induction of neural stem cell expansion during axolotl spinal cord regeneration. Elife, 4, e10230. 
SABIN, K., SANTOS-FERREIRA, T., ESSIG, J., RUDASILL, S. \& ECHEVERRI, K. 2015a. Dynamic membrane depolarization is an early regulator of ependymoglial cell response to spinal cord injury in axolotl. Dev Biol, 408, 14-25.

SABIN, K. Z., JIANG, P., GEARHART, M. D., STEWART, R. \& ECHEVERRI, K. 2019. AP-1(cFos/JunB)/miR-200a regulate the pro-regenerative glial cell response during axolotl spinal cord regeneration. Commun Biol, 2, 91.

SANCHEZ ALVARADO, A. \& TSONIS, P. A. 2006. Bridging the regeneration gap: genetic insights from diverse animal models. Nat Rev Genet., 11, 873-84.

SCHNAPP, E., KRAGL, M., RUBIN, L. \& TANAKA, E. M. 2005. Hedgehog signaling controls dorsoventral patterning, blastema cell proliferation and cartilage induction during axolotl tail regeneration. Development, 132, 3243-53.

SCHWANHAUSSER, B., BUSSE, D., LI, N., DITTMAR, G., SCHUCHHARDT, J., WOLF, J., CHEN, W. \& SELBACH, M. 2011. Global quantification of mammalian gene expression control. Nature, 473, 337-42.

SEHM, T., SACHSE, C., FRENZEL, C. \& ECHEVERRI, K. 2009. miR-196 is an essential early-stage regulator of tail regeneration, upstream of key spinal cord patterning events. Dev Biol, 334, 468-80.

SHTUTMAN, M., ZHURINSKY, J., SIMCHA, I., ALBANESE, C., D'AMICO, M., PESTELL, R. \& BEN-ZE'EV, A. 1999. The cyclin D1 gene is a target of the betacatenin/LEF-1 pathway. Proc Natl Acad Sci U S A, 96, 5522-7.

STOICK-COOPER, C., WEIDINGER, G., RIEHLE, K., HUBBERT, C., MAJOR, M., FAUSTO, N. \& MOON, R. 2007. Distinct Wnt signaling pathways have opposing roles in appendage regeneration. Development, 134, 479-89.

SU, J., ZHANG, A., SHI, Z., MA, F., PU, P., WANG, T., ZHANG, J., KANG, C. \& ZHANG, Q. 2012. MicroRNA-200a suppresses the Wnt/beta-catenin signaling pathway by interacting with beta-catenin. Int J Oncol, 40, 1162-70.

SUN, X., MARIANI, F. V. \& MARTIN, G. R. 2002. Functions of FGF signalling from the apical ectodermal ridge in limb development. Nature, 418, 501-508.

TANAKA, E. M. \& WEIDINGER, G. 2008. Heads or tails: can Wnt tell which one is up? Nat Cell Biol, 10, 122-4.

TANIGUCHI, Y., KURTH, T., WEICHE, S., REICHELT, S., TAZAKI, A., PERIKE, S., KAPPERT, V. \& EPPERLEIN, H. H. 2017. The posterior neural plate in axolotl gives rise to neural tube or turns anteriorly to form somites of the tail and posterior trunk. Dev Biol, 422, 155-170.

TRUMBACH, D. \& PRAKASH, N. 2015. The conserved miR-8/miR-200 microRNA family and their role in invertebrate and vertebrate neurogenesis. Cell Tissue Res, 359, 161-77.

TSAKIRIDIS, A., HUANG, Y., BLIN, G., SKYLAKI, S., WYMEERSCH, F., OSORNO, R., ECONOMOU, C., KARAGIANNI, E., ZHAO, S., LOWELL, S. \& WILSON, V. 2014. Distinct Wnt-driven primitive streak-like populations reflect in vivo lineage precursors. Development, 141, 1209-21.

TSAKIRIDIS, A. \& WILSON, V. 2015. Assessing the bipotency of in vitro-derived neuromesodermal progenitors. F1000Res, 4, 100.

TURNER, D. A., HAYWARD, P. C., BAILLIE-JOHNSON, P., RUE, P., BROOME, R., FAUNES, F. \& MARTINEZ ARIAS, A. 2014a. Wnt/beta-catenin and FGF signalling direct the specification and maintenance of a neuromesodermal axial 
992

993

994

995

996

997

998

999

1000

1001

1002

1003

1004

1005

1006

1007

1008

1009

1010

1011

1012

1013

1014

1015

1016

1017

1018

1019

1020

1021

1022

1023

1024

1025

1026

1027

1028

1029

1030

1031

1032

1033

1034

1035

1036

1037

1038 progenitor in ensembles of mouse embryonic stem cells. Development, 141, 424353.

TURNER, D. A., HAYWARD, P. C., BAILLIE-JOHNSON, P., RUÉ, P., BROOME, R., FAUNES, F. \& MARTINEZ ARIAS, A. 2014b. Wnt/ $\beta$-catenin and FGF signalling direct the specification and maintenance of a neuromesodermal axial progenitor in ensembles of mouse embryonic stem cells. Development, 141, 424353.

TZOUANACOU, E., WEGENER, A., WYMEERSCH, F. J., WILSON, V. \& NICOLAS, J. F. 2009. Redefining the progression of lineage segregations during mammalian embryogenesis by clonal analysis. Dev Cell, 17, 365-76.

VALLEJO, D. M., CAPARROS, E. \& DOMINGUEZ, M. 2011. Targeting Notch signalling by the conserved miR-8/200 microRNA family in development and cancer cells. EMBO J, 30, 756-69.

WANG, G., GUO, X., HONG, W., LIU, Q., WEI, T., LU, C., GAO, L., YE, D., ZHOU, Y., CHEN, J., WANG, J., WU, M., LIU, H. \& KANG, J. 2013. Critical regulation of miR-200/ZEB2 pathway in Oct4/Sox2-induced mesenchymal-to-epithelial transition and induced pluripotent stem cell generation. Proc Natl Acad Sci U S A, 110, 2858-63.

WEHNER, D., TSAROUCHAS, T. M., MICHAEL, A., HAASE, C., WEIDINGER, G., REIMER, M. M., BECKER, T. \& BECKER, C. G. 2017. Wnt signaling controls pro-regenerative Collagen XII in functional spinal cord regeneration in zebrafish. Nat Commun, 8, 126.

WILSON, S. I., GRAZIANO, E., HARLAND, R., JESSELL, T. M. \& EDLUND, T. 2000. An early requirement for FGF signalling in the acquisition of neural cell fate in the chick embryo. Curr Biol, 10, 421-9.

WYMEERSCH, F. J., HUANG, Y., BLIN, G., CAMBRAY, N., WILKIE, R., WONG, F. C. \& WILSON, V. 2016. Position-dependent plasticity of distinct progenitor types in the primitive streak. Elife, 5, e10042.

YAMAGUCHI, T. P., TAKADA, S., YOSHIKAWA, Y., WU, N. \& MCMAHON, A. P. 1999. T (Brachyury) is a direct target of Wnt3a during paraxial mesoderm specification. Genes Dev, 13, 3185-90.

ZAKANY, J. \& DUBOULE, D. 1993. Correlation of expression of Wnt-1 in developing limbs with abnormalities in growth and skeletal patterning. Nature, 362, 546-9.

ZARAVINOS, A. 2015. The Regulatory Role of MicroRNAs in EMT and Cancer. $J$ Oncol, 2015, 865816.

ZHANG, F., CLARKE, J. D. \& FERRETTI, P. 2000. FGF-2 Up-regulation and proliferation of neural progenitors in the regenerating amphibian spinal cord in vivo. Dev Biol, 225, 381-91.

ZHANG, F., CLARKE, J. D., SANTOS-RUIZ, L. \& FERRETTI, P. 2002a. Differential regulation of fibroblast growth factor receptors in the regenerating amphibian spinal cord in vivo. Neuroscience, 114, 837-48.

ZHANG, F., CLARKE, J. D. W. \& FERRETTI, P. 2002b. Differential regulation of FGFRs in the regenerating amphibian spinal cord. Neuroscience, 114, 837-848.

ZUKOR, K. A., KENT, D. T. \& ODELBERG, S. J. 2011. Meningeal cells and glia establish a permissive environment for axon regeneration after spinal cord injury in newts. Neural Dev, 6, 1. 


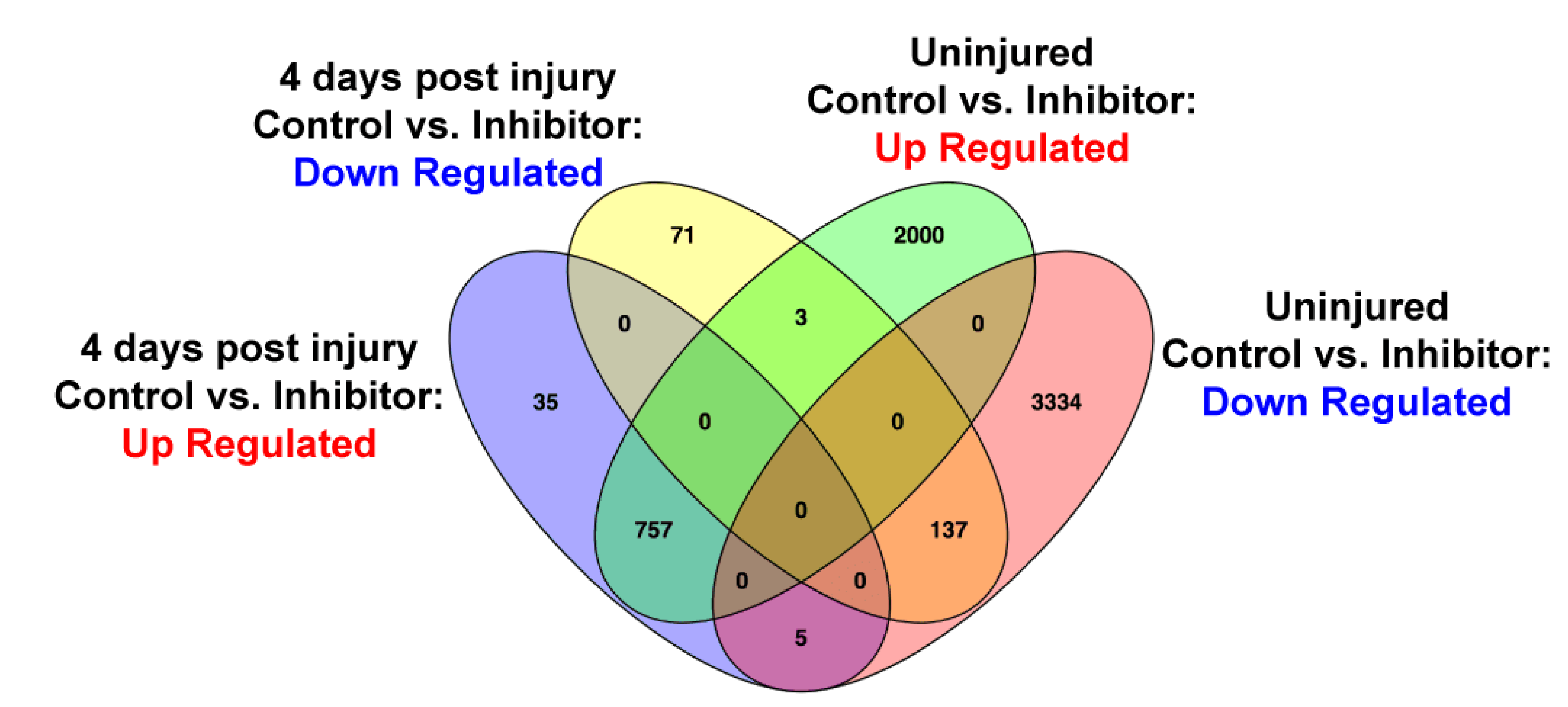

B.

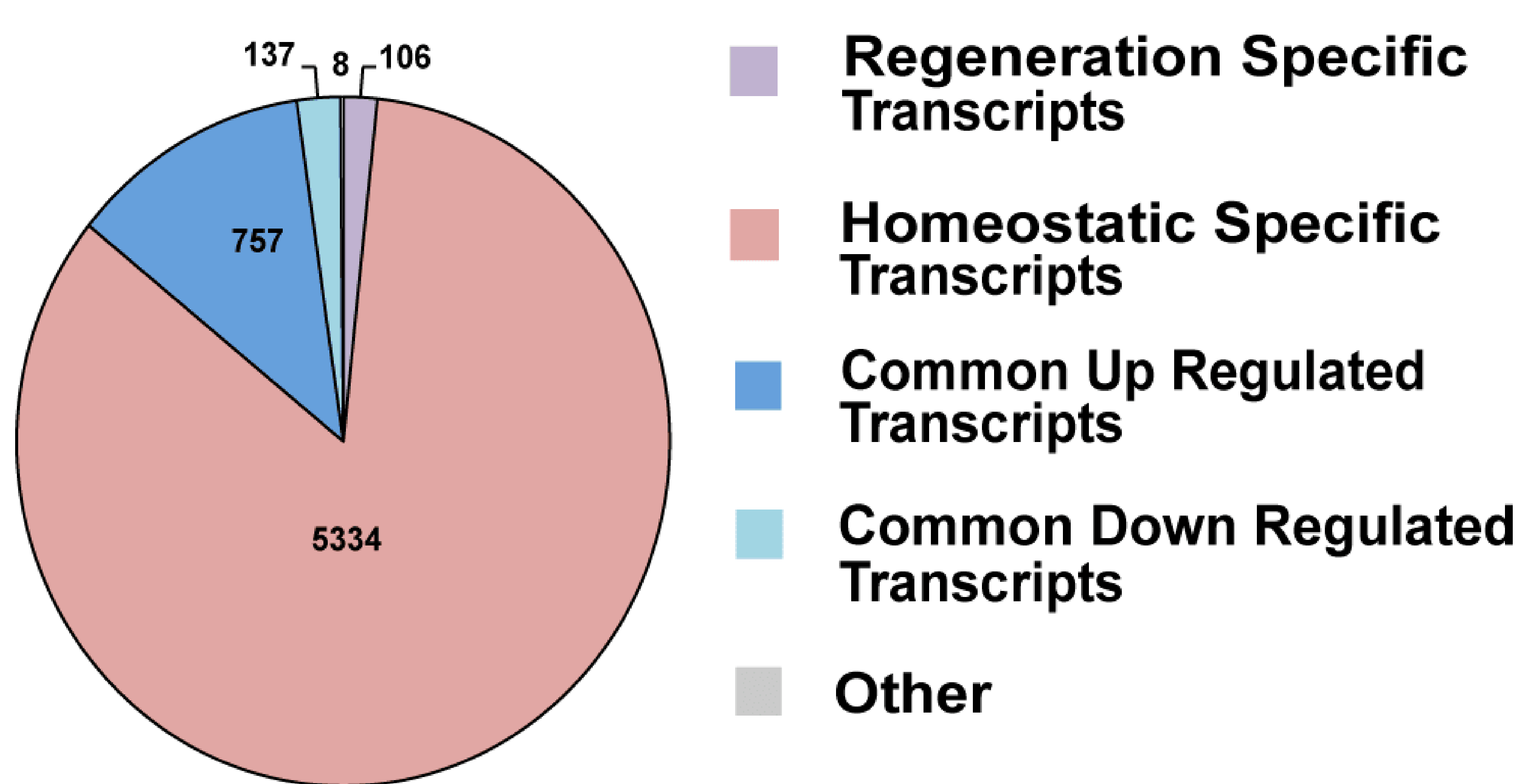

D.

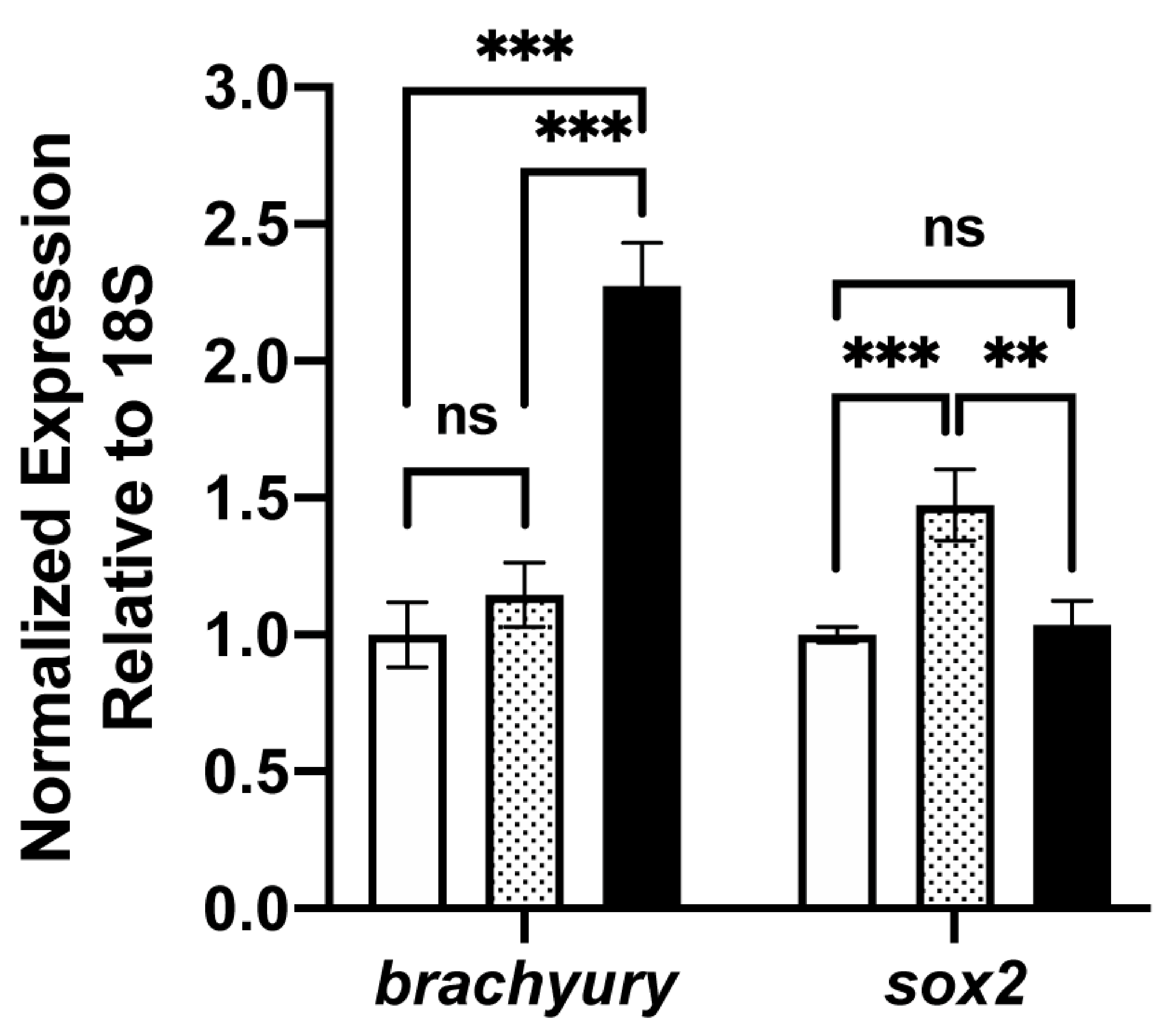

Uninjured

4dpi Control

4dpi Inhibitor

E.

C.

Figure 2

A. B.
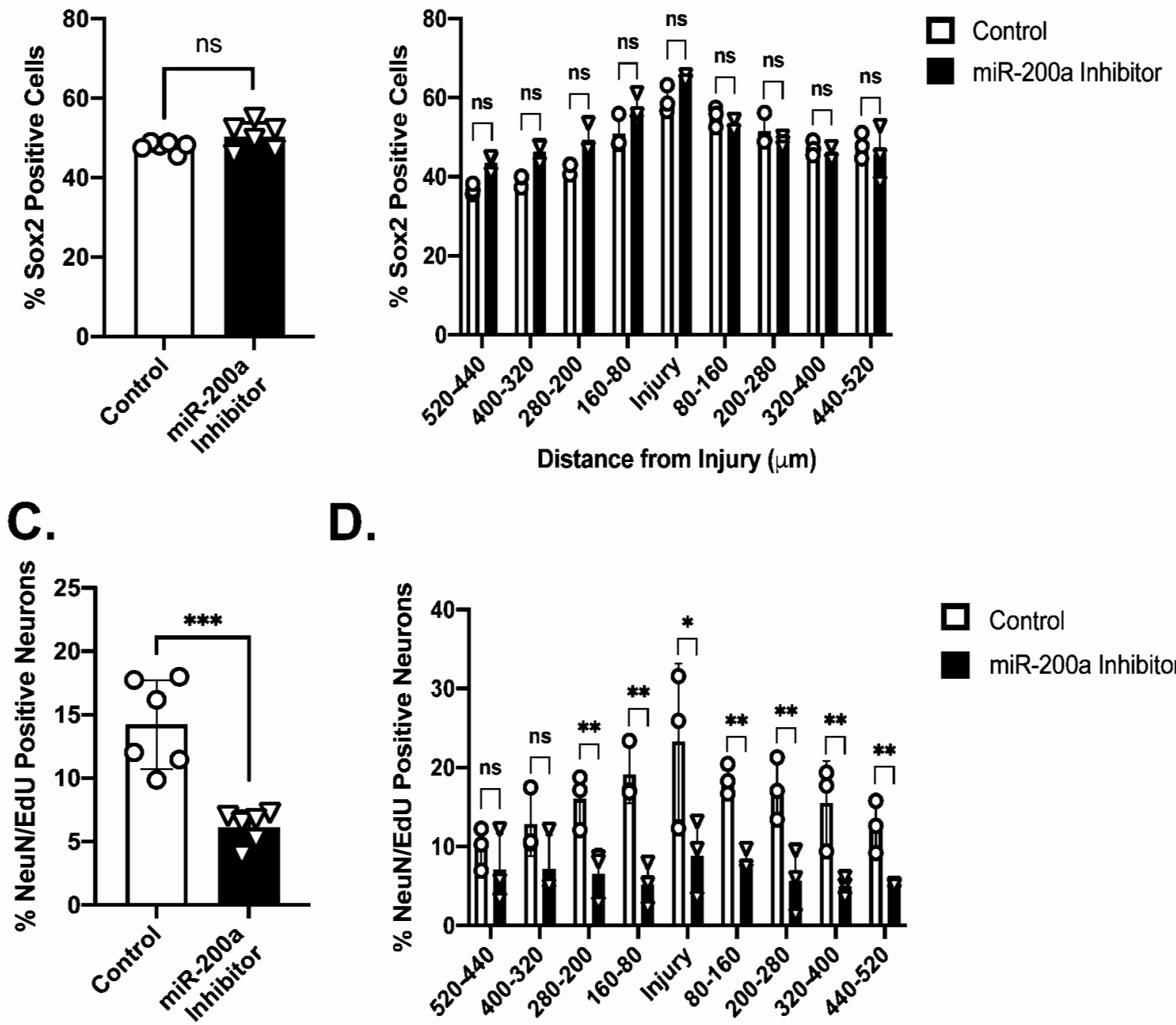

D.

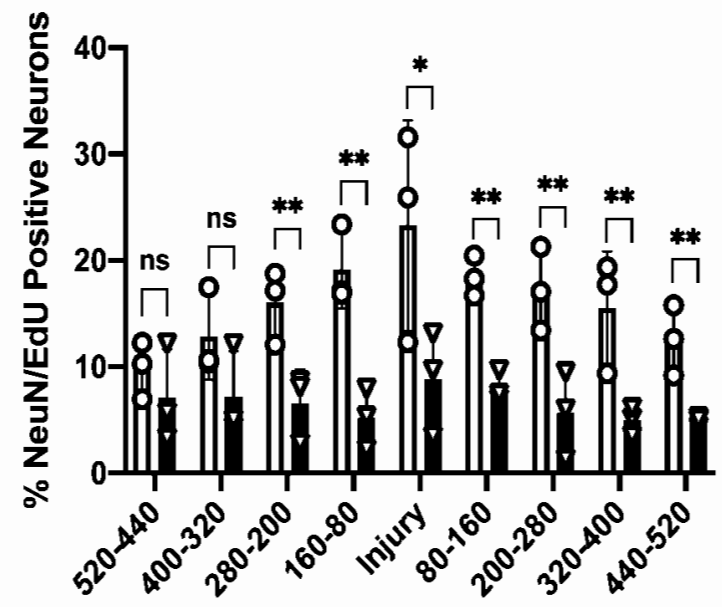

a Control

miR-200a Inhibitor

Distance from Injury $(\mu \mathrm{m})$ 
Figure 3
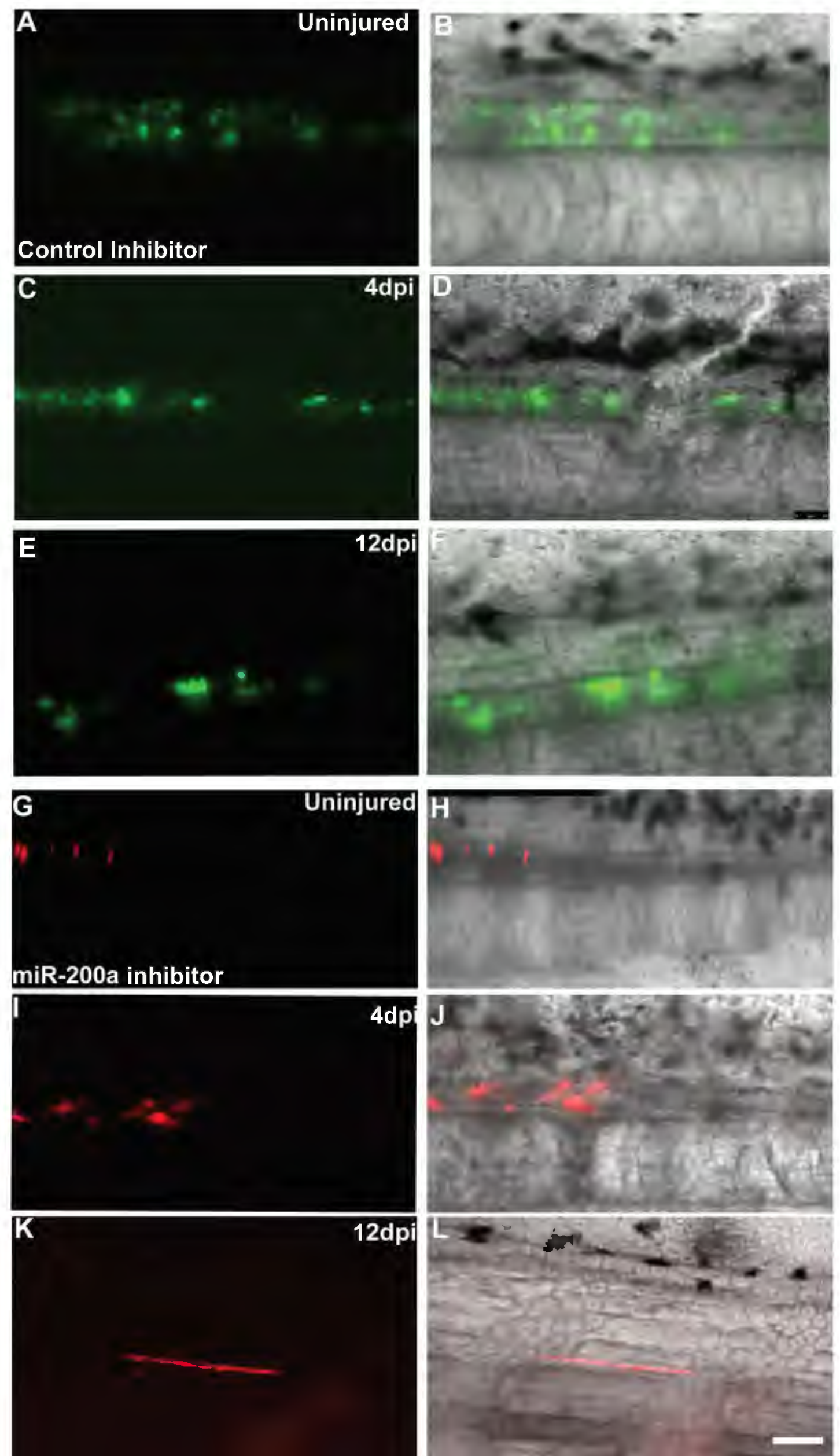


\section{Figure 4}

bioRxiv preprint doi: https://doi.org/10.1101/2021.07.21.453081; this version posted September 2, 2021. The copyright holder for this preprint (which was not certified by peer review) is the authorffunder. All rights reserved. No retse allowed without permission.
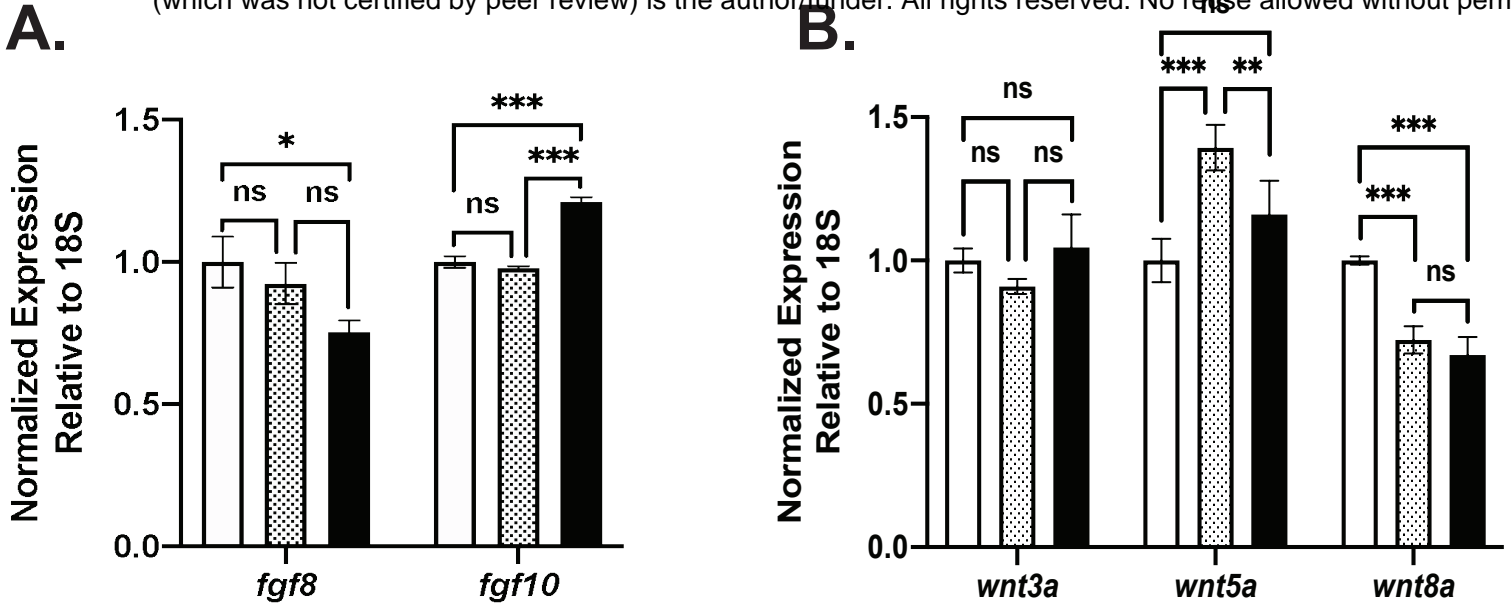

\section{4dpi Control}

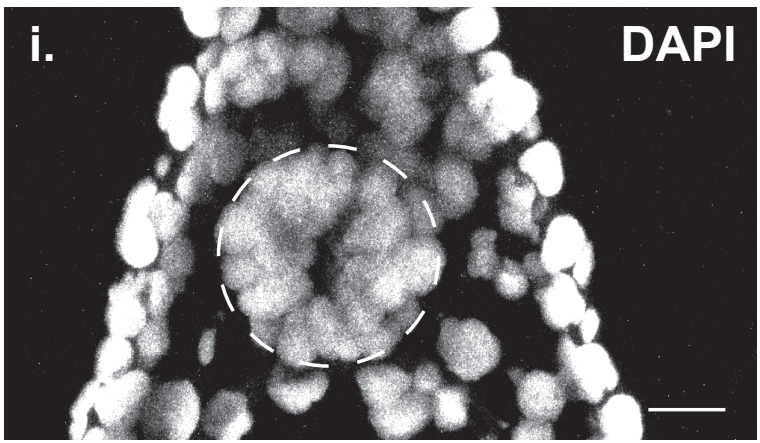

D. 4dpi Inhibitor
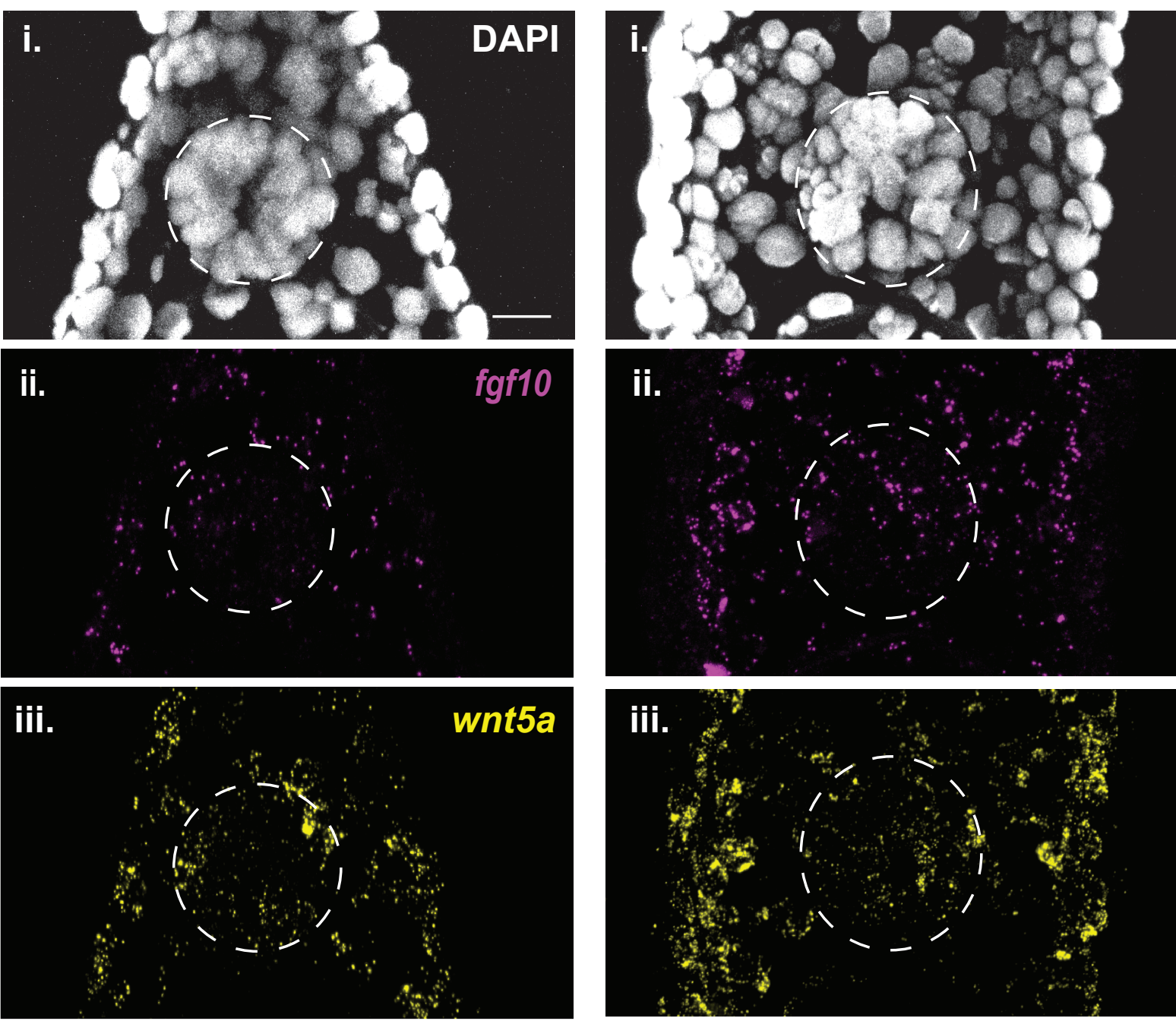

ii.
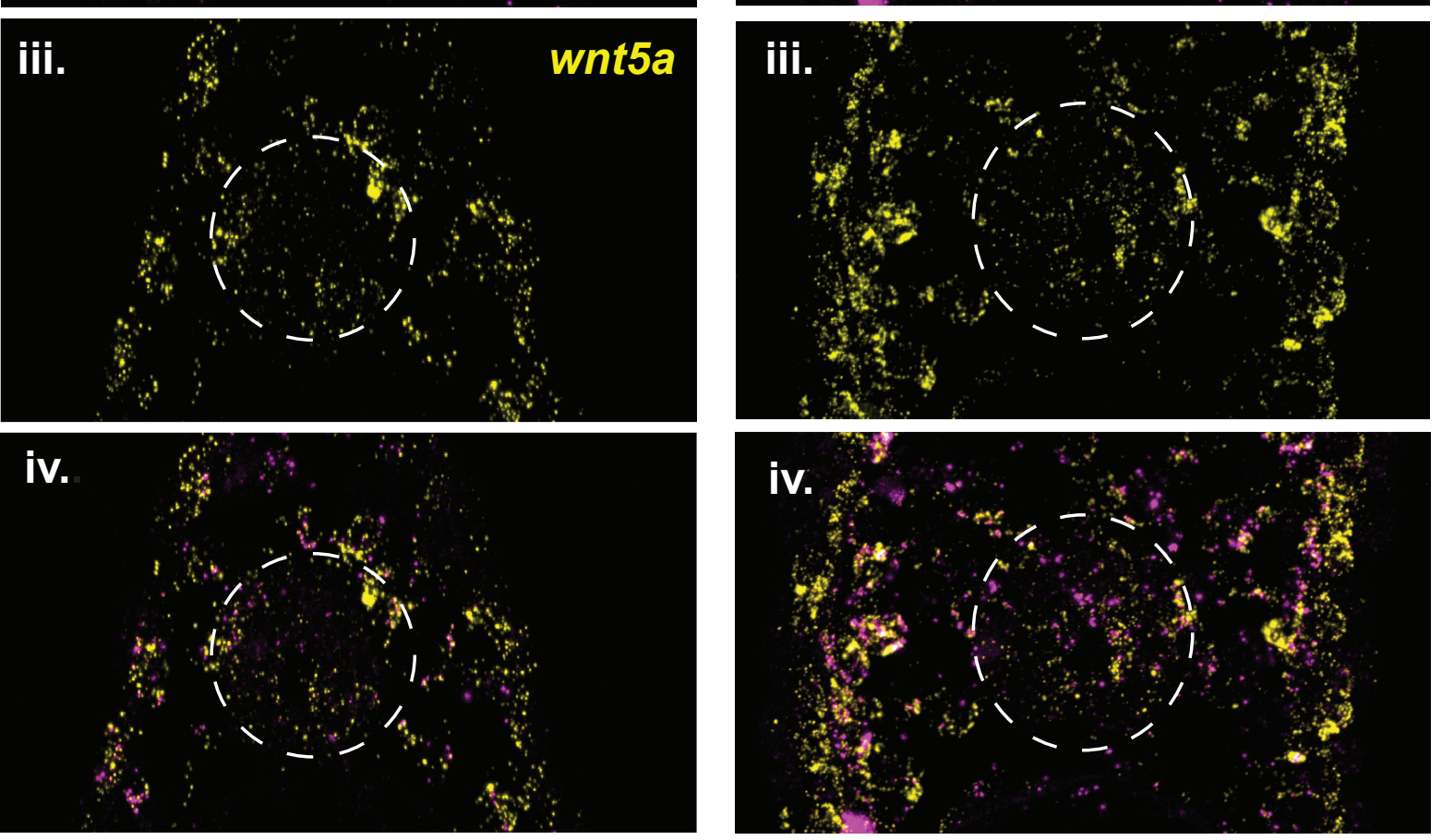


\section{Figure 5}

bioRxiv preprint doi: https://doi.org/10.1101/2021.07.21.453081; this version posted September 2, 2021. The copyright holder for this preprint (which was not certified by peer review) is the author/funder. All rights reserved. No reuse allowed without permission.

\section{A. Uninjured}

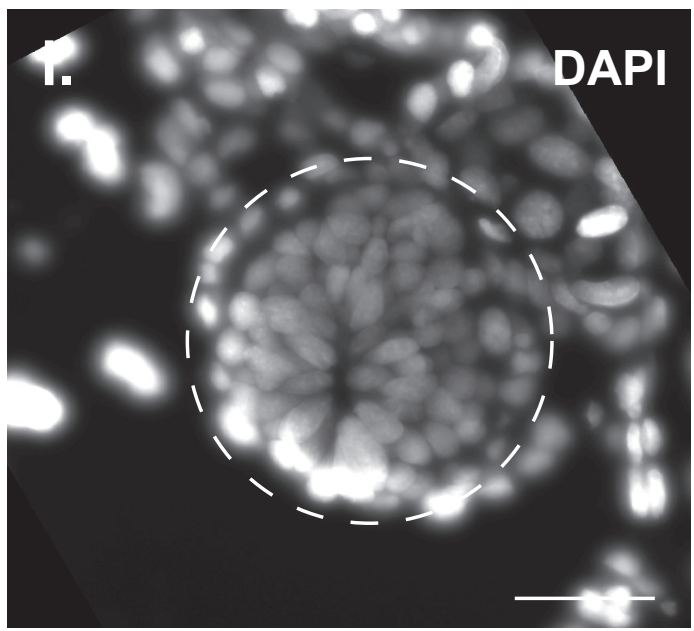

ii.
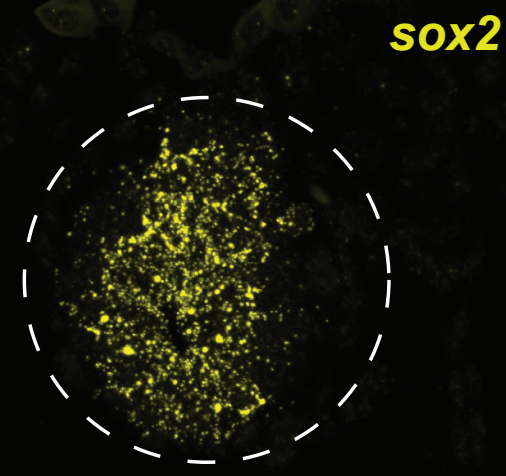

iti.

\section{brachyury}

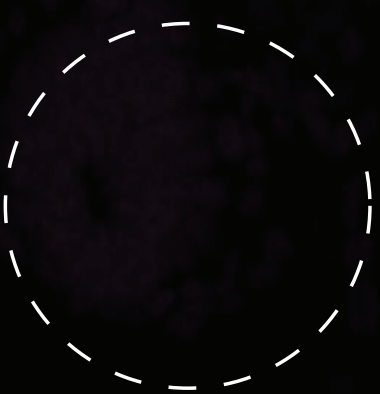

\section{iv.}

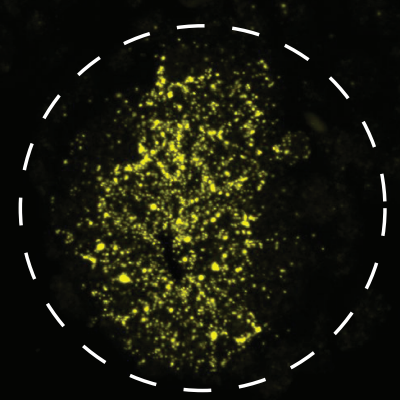

\section{B. 7dpa}

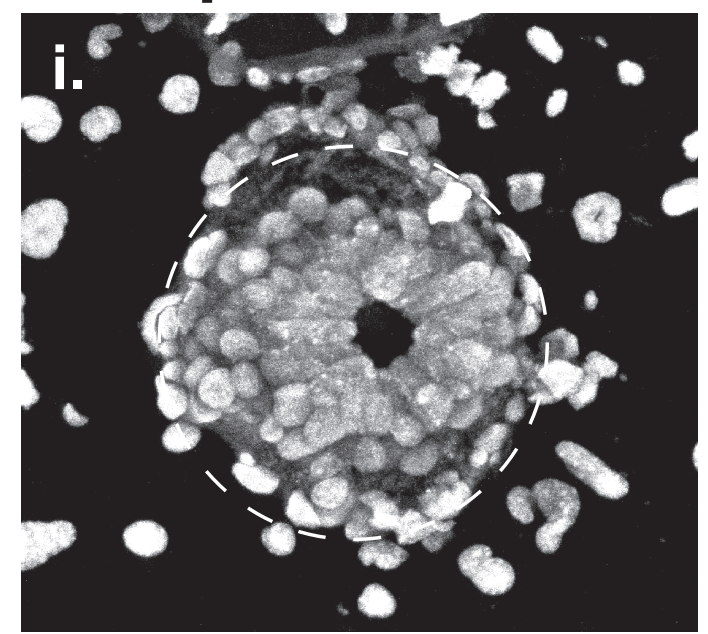

it.

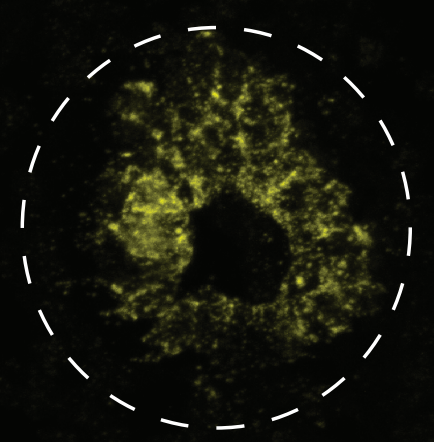

iti.

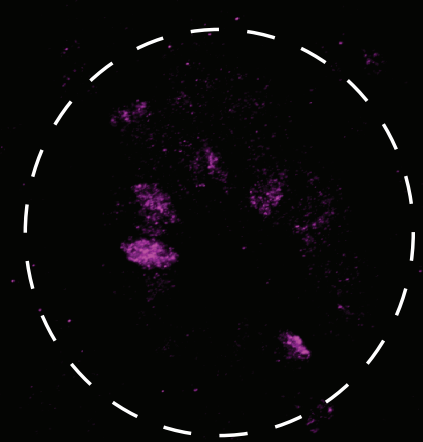

iv.

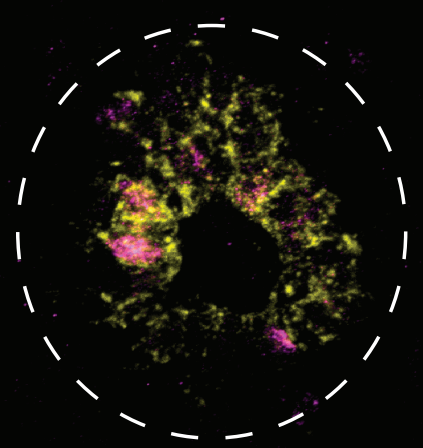




\section{Spinal cord injury}
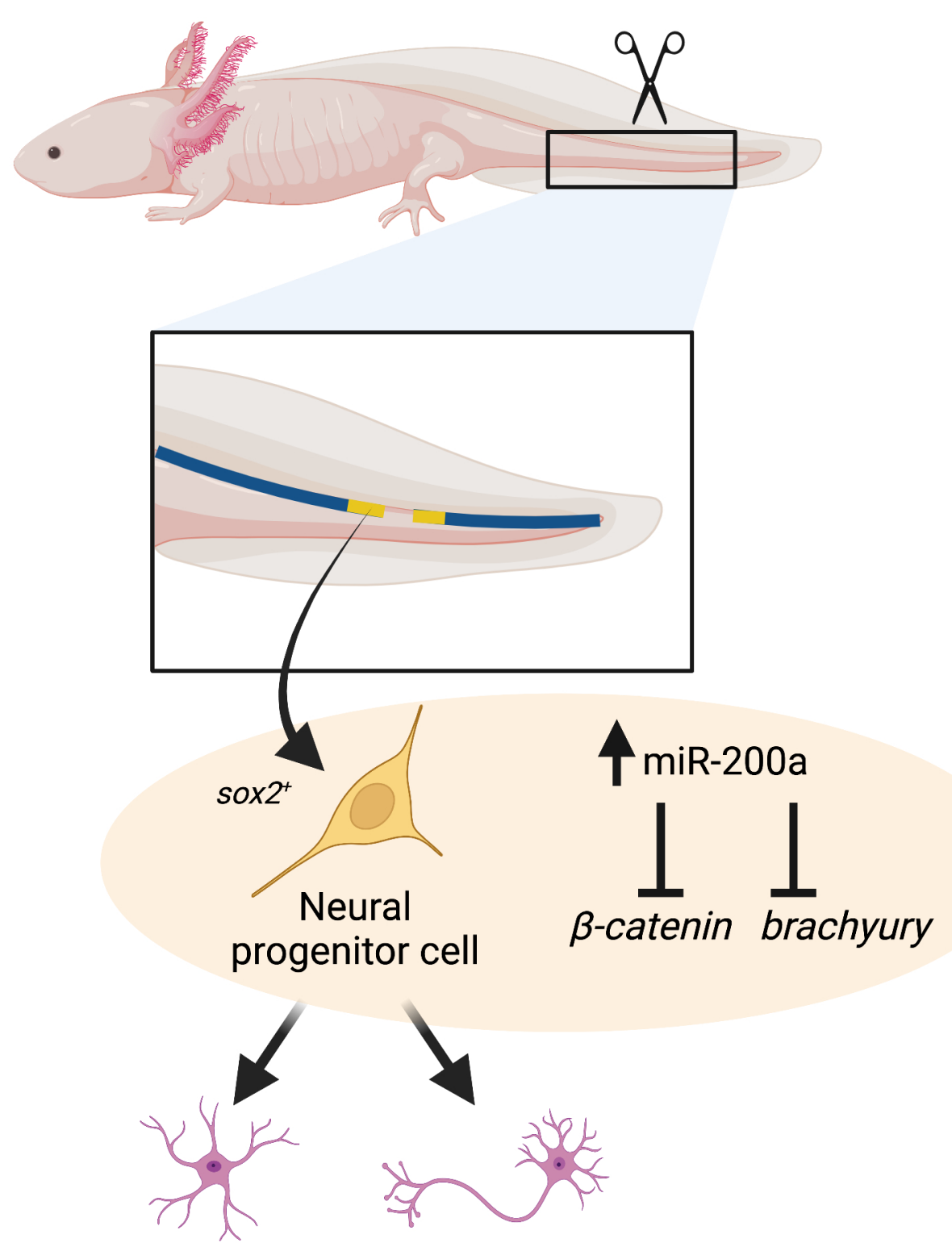

Glial cell

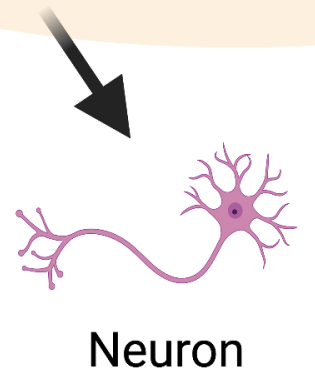

Spinal cord amputation
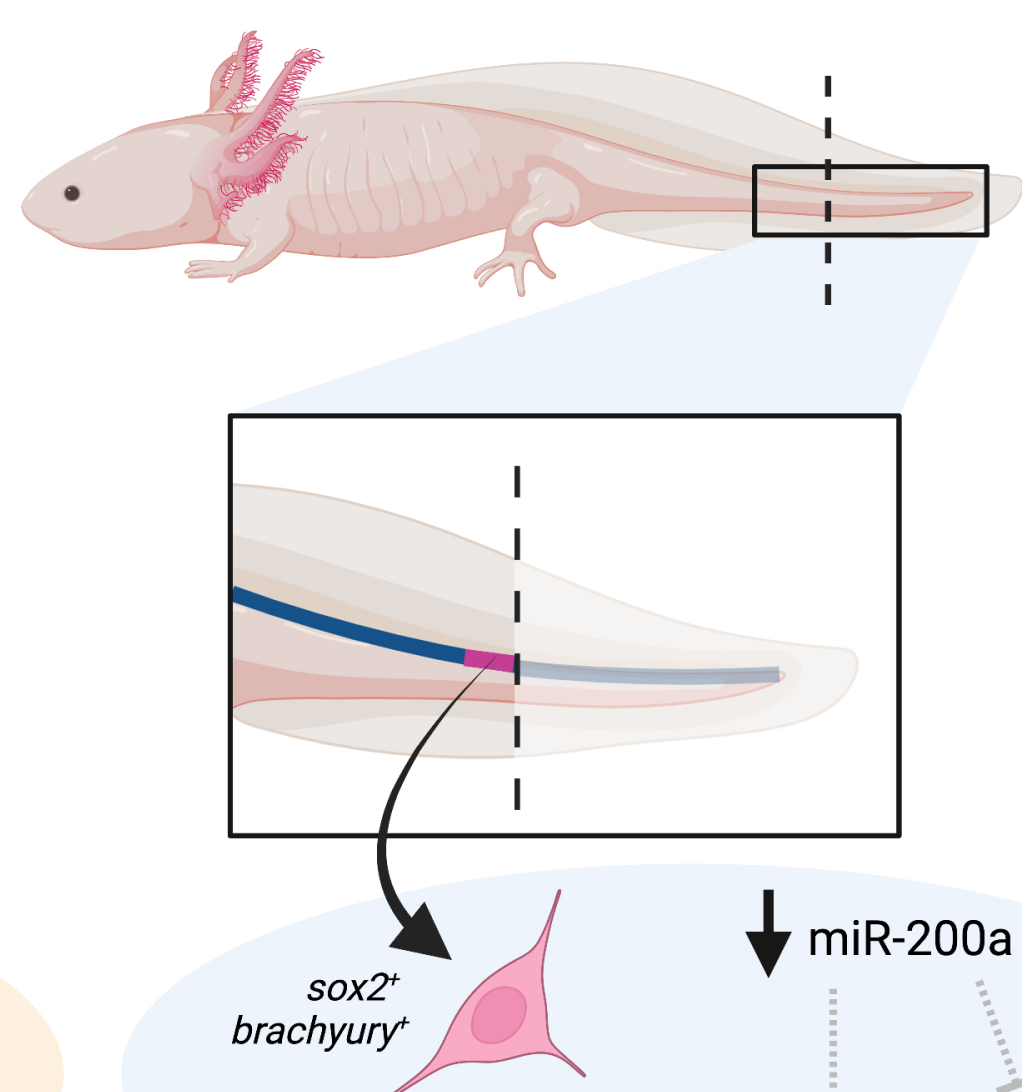

Bipotent $\uparrow \beta$-catenin $\uparrow b r a c h y u r y$ progenitor cell

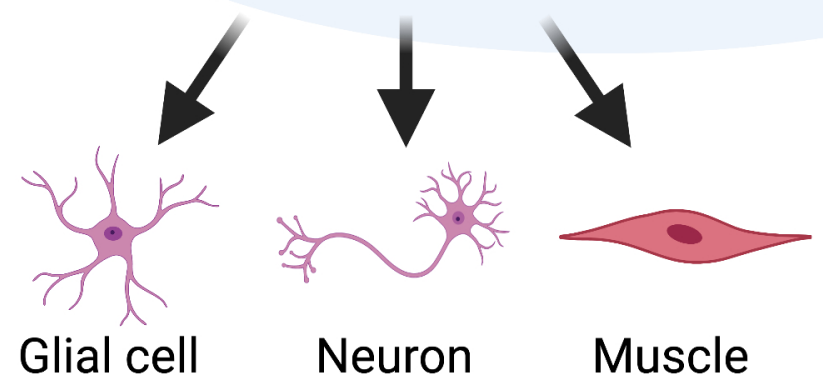

